\title{
Test Plan for Air Monitoring During the Cryogenic Retrieval Demonstration
}

\author{
Eileen Yokuda
}

Published June 1992

\author{
Idaho National Engineering Laboratory \\ EG\&G Idaho, Inc. \\ Idaho Falls, Idaho 83415
}

Prepared for the

U.S. Department of Energy

Office of Environmental Restoration and Waste Management

Under DOE Idaho Fleld Office

Contract DE-AC07-761D01570 
Test Plan for Air Monitoring During the Cryogenic Retrieval Demonstration

EGG-WTD-10320

Prepared by:

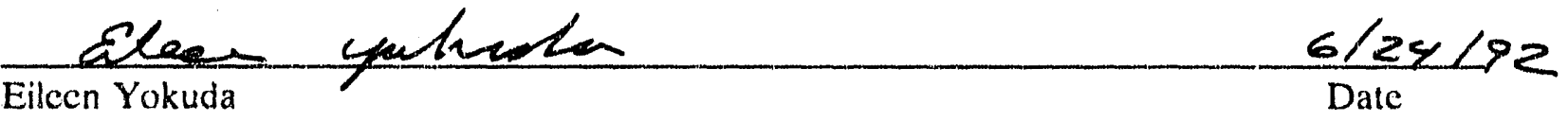

Approved by:
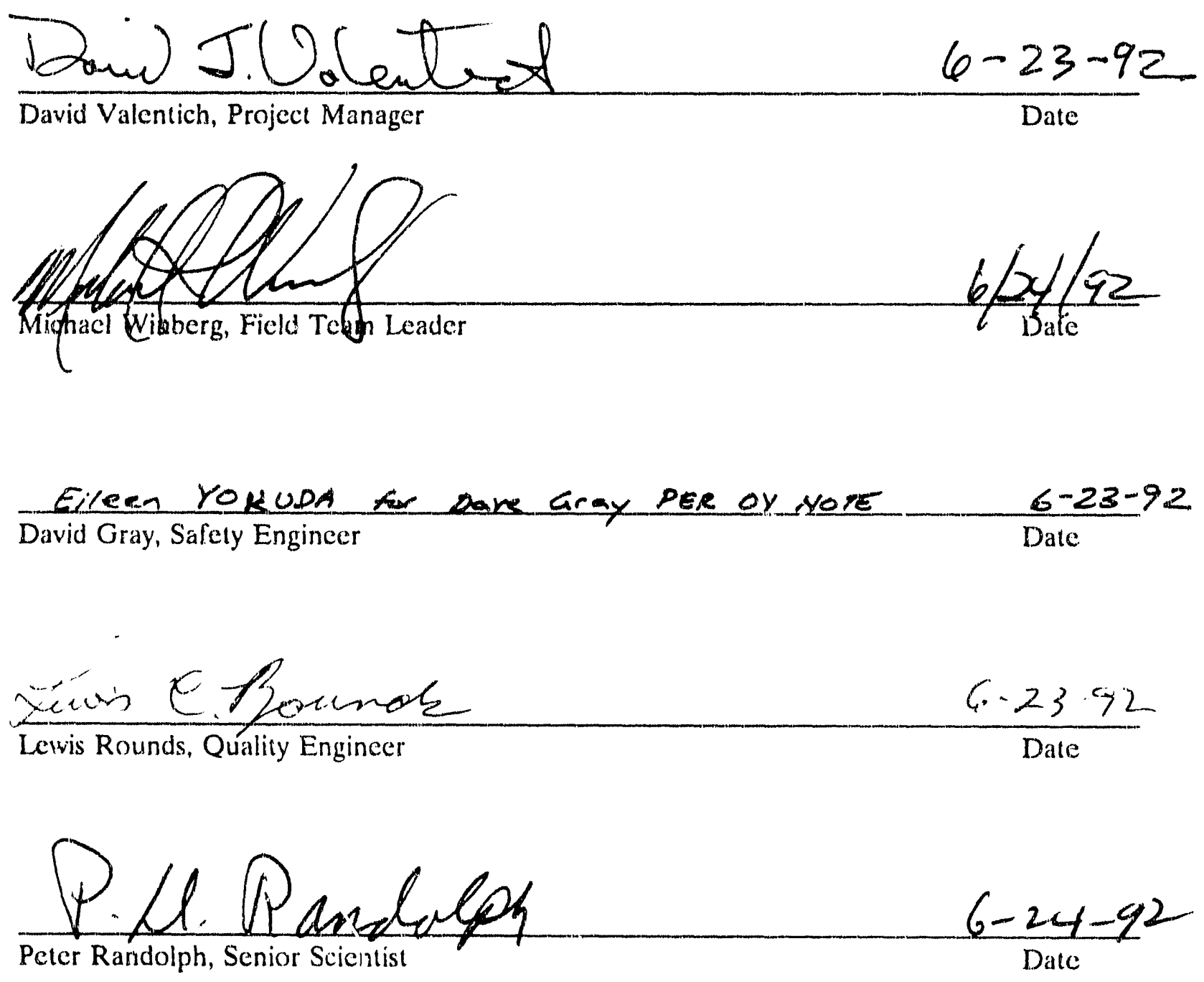


\begin{abstract}
This report presents a test plan for air monitoring during the Cryogenic Retrieval Demonstration (CRD). Air monitors will be used to sample for the tracer elements neodymium, torbium, ytterbium, and dysprosium. The results from this air monitoring will be used to determine if the CRD is successful in controlling dust and minimizing contamination. Procedures and equinment specifications for the test are included.
\end{abstract}




\section{CONTENTS}

ABSTRACT $\ldots \ldots \ldots \ldots \ldots \ldots \ldots \ldots \ldots \ldots \ldots \ldots \ldots \ldots \ldots \ldots \ldots \ldots \ldots$

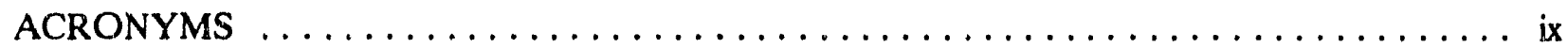

1. INTRODUCTION $\ldots \ldots \ldots \ldots \ldots \ldots \ldots \ldots \ldots \ldots \ldots \ldots \ldots \ldots \ldots \ldots \ldots$

1.1 Technology Description and Background $\ldots \ldots \ldots \ldots \ldots \ldots \ldots \ldots \ldots$

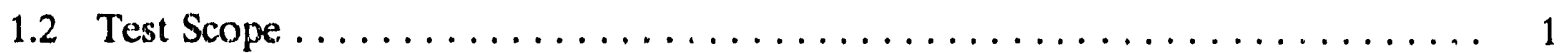

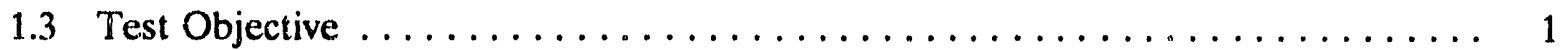

2. ORGANIZATION AND RESPONSIBILITIES $\ldots \ldots \ldots \ldots \ldots \ldots \ldots \ldots \ldots \ldots$

2.1 Test Personnel Qualifications and Training $\ldots \ldots \ldots \ldots \ldots \ldots \ldots \ldots$

3. DESCRIPTION OF TEST $\ldots \ldots \ldots \ldots \ldots \ldots \ldots \ldots \ldots \ldots \ldots \ldots \ldots \ldots \ldots$

3.1 Key Input and Output Conditions $\ldots \ldots \ldots \ldots \ldots \ldots \ldots \ldots \ldots \ldots \ldots$

3.2 Number of Tests, Location, and Schedule $\ldots \ldots \ldots \ldots \ldots \ldots \ldots \ldots$

3.3 Test Method and Uncertainties $\ldots \ldots \ldots \ldots \ldots \ldots \ldots \ldots \ldots \ldots \ldots$

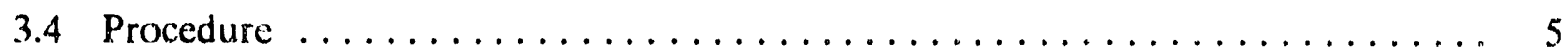

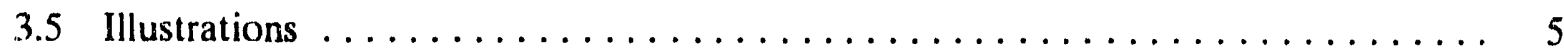

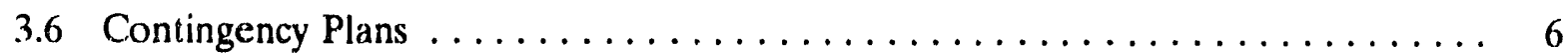

3.7 Performance Objectives $\ldots \ldots \ldots \ldots \ldots \ldots \ldots \ldots \ldots \ldots \ldots \ldots \ldots \ldots$

4. SEQUENCE OF EVENTS $\ldots \ldots \ldots \ldots \ldots \ldots \ldots \ldots \ldots \ldots \ldots \ldots \ldots \ldots$

5. SAMPLING AND DATA COLLECTION $\ldots \ldots \ldots \ldots \ldots \ldots \ldots \ldots \ldots \ldots$

5.1 Chain of Custody $\ldots \ldots \ldots \ldots \ldots \ldots \ldots \ldots \ldots \ldots \ldots \ldots \ldots \ldots \ldots \ldots \ldots$

5.2 PreSampling Filter Weighing $\ldots \ldots \ldots \ldots \ldots \ldots \ldots \ldots \ldots \ldots \ldots \ldots \ldots$

5.3 Installing Filters on the Hi-Volume Air Monitors $\ldots \ldots \ldots \ldots \ldots \ldots \ldots$

5.4 Removing the Filters from the Hi-Volume Air Monitors $\ldots \ldots \ldots \ldots \ldots \ldots \ldots 11$

5.5 Installing Filters into the Low-Volume Air Samplers $\ldots \ldots \ldots \ldots \ldots \ldots \ldots \ldots$ 
5.6 Removing and Exchanging Filters from the Low-Volume Air Samplers . . . . . 11

5.7 PostSampling Filter Weighing $\ldots \ldots \ldots \ldots \ldots \ldots \ldots \ldots \ldots \ldots \ldots \ldots \ldots$

6. DOCUMENT CONTROL $\ldots \ldots \ldots \ldots \ldots \ldots \ldots \ldots \ldots \ldots \ldots \ldots \ldots \ldots$

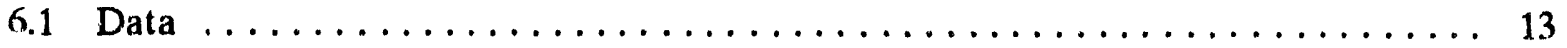

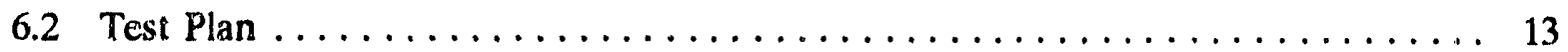

6.3 Logbooks .................................. 13

7. ANALYTICAL METHODS $\ldots \ldots \ldots \ldots \ldots \ldots \ldots \ldots \ldots \ldots \ldots \ldots \ldots \ldots$

8. DATA REDUCTION, VALIDATION, AND VERIFICATION $\ldots \ldots \ldots \ldots \ldots$

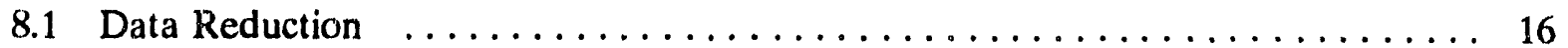

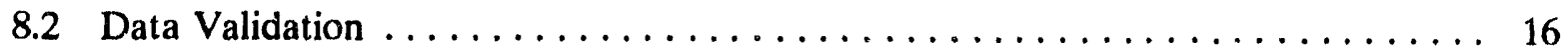

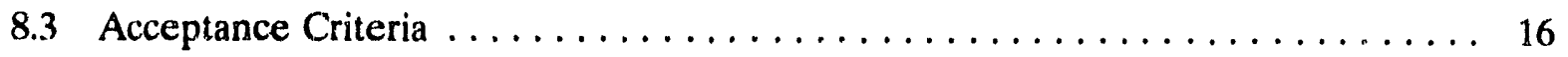

9. QUALITY ASSURANCE $\ldots \ldots \ldots \ldots \ldots \ldots \ldots \ldots \ldots \ldots \ldots \ldots \ldots \ldots \ldots$

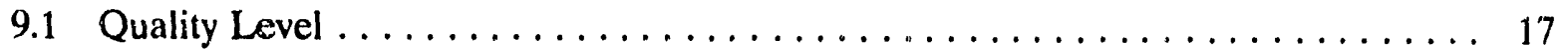

9.2 Quality Control Methods $\ldots \ldots \ldots \ldots \ldots \ldots \ldots \ldots \ldots \ldots \ldots \ldots \ldots$

9.3 Completeness $\ldots \ldots \ldots \ldots \ldots \ldots \ldots \ldots \ldots \ldots \ldots \ldots \ldots \ldots \ldots \ldots \ldots$

9.4 Internal Audit Procedures $\ldots \ldots \ldots \ldots \ldots \ldots \ldots \ldots \ldots \ldots \ldots \ldots \ldots$

10. EQUIPMENT AND INSTRUMENTS $\ldots \ldots \ldots \ldots \ldots \ldots \ldots \ldots \ldots \ldots \ldots$

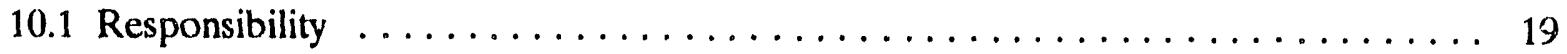

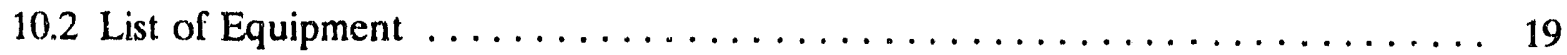

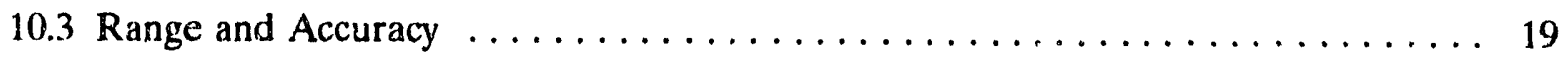

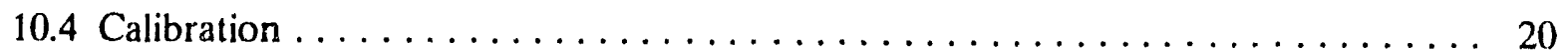

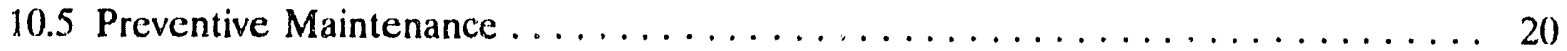

11. SUPPLIES, UTILITIES, AND FACILITIES $\ldots \ldots \ldots \ldots \ldots \ldots \ldots \ldots \ldots$

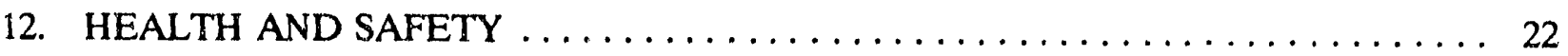


12.1 Training $\ldots \ldots \ldots \ldots \ldots \ldots \ldots \ldots \ldots \ldots \ldots \ldots \ldots \ldots \ldots \ldots \ldots \ldots \ldots \ldots \ldots, 22$

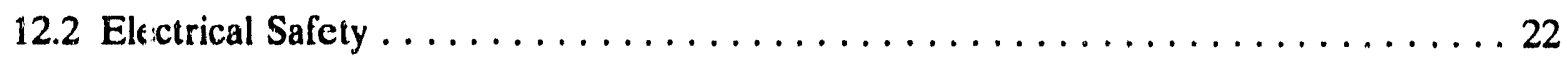

13. RESIDUALS MANAGEMENT $\ldots \ldots \ldots \ldots \ldots \ldots \ldots \ldots \ldots \ldots \ldots \ldots \ldots \ldots \ldots$

Appendix A-Assumptions on Tracer Movement $\ldots \ldots \ldots \ldots \ldots \ldots \ldots \ldots \ldots \ldots$ A-1

FIGURES

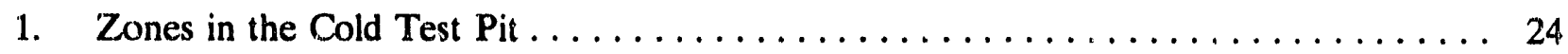

2. Top view of wet and dry portions of the pit $\ldots \ldots \ldots \ldots \ldots \ldots \ldots \ldots \ldots \ldots \ldots \ldots \ldots \ldots, 25$

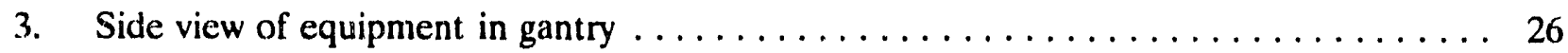

4. Side view of low-volume monitor locations $\ldots \ldots \ldots \ldots \ldots \ldots \ldots \ldots \ldots \ldots \ldots \ldots \ldots \ldots$

5. Location of hi-volume monitors $\ldots \ldots \ldots \ldots \ldots \ldots \ldots \ldots \ldots \ldots \ldots \ldots \ldots$

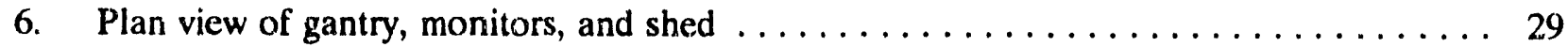

7. Schematic of connections between low-volume monitors and pumps $\ldots \ldots \ldots \ldots \ldots$

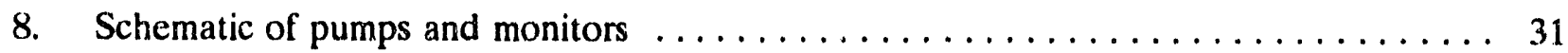

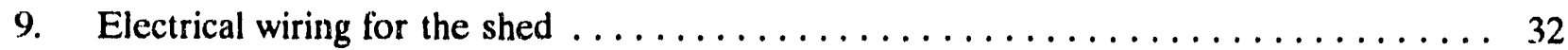

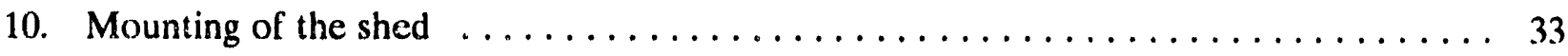

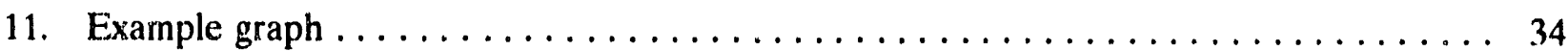

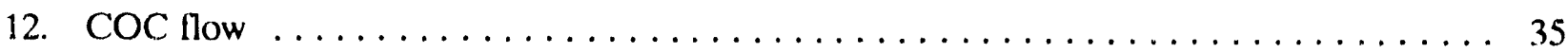

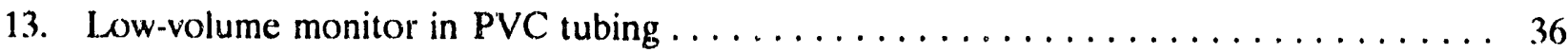

\section{TABLES}

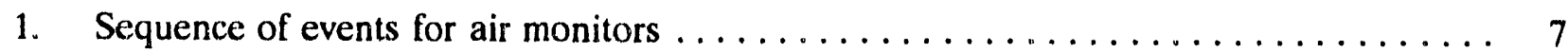

2. Calculation of upper prediction limits when sample size $=10$. Values are in units of $\mu \mathrm{g} / \mathrm{g}$ dust and assume the concentrations are corrected for blank contamination ...... 18

3. Calculation of upper prediction limits when sample size $=5$. Values are in units of $\mu \mathrm{g} / \mathrm{g}$ dust and assume the concentrations are corrected for blank contamination ...... 18 


\section{ACRONYMS}

\begin{tabular}{ll} 
BWID & Buried Waste Integrated Demonstration \\
CDC & Chain of Custody \\
CR & Cryogenic Retrieval \\
CRD & Cryogenic R trieval Demonstration \\
CTP & Cold Test Pit \\
DQO & Data Quality Objectives \\
ECU & Environmental Chemistry Urit \\
EPA & Environmental Protection Agrency \\
ICP & Inductively Coupled Plasma \\
INEL & Idaho National Engineering Laboratory \\
MS & Mass Spectrometry \\
QA & Quality Assurance \\
RSD & Relative Standard Deviation \\
RWMC & Radioactive Waste Management Complex \\
S\&CL & Standards and Calibration Laboratory \\
SCBA & \\
\hline
\end{tabular}




\section{Test Plan for Air Monitoring During the Cryogenic Retrieval Demonstration}

\section{INTRODUCTION}

\subsection{Technology Description and Background}

The purpose of this test plan is to outline the methods and practices that will be used for air monitoring during the Cryogenic Retrieval Demonstration (CRD). The CRD will consist of freezing and exhuming eight separate blocks, each about 450 cubic feet. The project will begin in early July 1992, and last six to eight weeks. The air monitoring will be in place to aid in determining if the $\mathrm{CRD}$ is successful in minimizing dust generation.

\subsection{Test Scope}

The Cold Test Pit (CTP) has been spiked with four rare-earth tracers, neodymium, dysprosium, terbium, and ytterbium. The scope of the air monitoring test is to monitor the air around the CTP during portions of the CRD to determine if significant amounts of these tracers are released during the CRD.

\subsection{Test Objective}

The basic hypothesis behind the air monitoring is that if the CRD is successful, and no significant amount of tracer is released to the atmosphere, the air monitors will only pick $p$ the natural background level for the tracers. The objective of the air monitoring test is to determine if significant amounts of tracers are released during the CRD.

The term "significant amount" will be defined as a threshold concentration level. The concentration level is defined in terms of a ratio of milligrams of the tracer to kilograms of dust. The value of this ratio will be different for each of the tracers. These threshold values depend upon the statistical distribution of the natural background levels for each of the tracers. An outline of how these levels are determined is given in Appendix A.

The Data Quality Objectives (DQO) for the placement of the samplers is to have the monitors located so that they will capture a statistically significant sample of the dust and air. The DQO for the individual filter samples is to see if the tracer concentration is above or below the threshold concentration. If the concentration of a tracer on any filter is above the specified threshold concentration, the portion of the test in which that sample was taken will be considered a failure in terms of the ability of Cryogenic Retrieval (CR) to minimize the dust generation during retrieval.

Quality assurance objectives are defined in Section 9. Instrument precision is addressed in Section 10. 


\section{ORGANIZATION AND RESPONSIBILITIES}

\section{Project Manger}

Dave Valentich

The project manager is responsible for seeing that all of the tasks associated with the CRD are completed.

\section{Task Manager}

\section{Eileen Yokuda}

The task manager is responsible for ensuring that all of the sampling and analyses will meet the Data Quality Objectives (DQO) of the Cryogenic Retrieval Demonstration.

\section{Quality Engineer}

Lewis Rounds

The quality engineer will ensure that this document satisfies QPP-337 and QPP-337, Addendum for the Cryogenic Retrieval Demonstration.

\section{Chemists}

Shelly Sailer

Mary Verwolf

The chemists will be performing the analyses of the air filters for rare-carth tracers.

\section{Air Monitoring Equipment Coordinator}

\section{Mike Winberg}

The air monitoring equipment coordinator will ensure that all of the air monitoring equipment is available, calibrated, and in good working order.

\section{Ficld Leader for Air Monitor Sampling}

\section{Mike Winberg}

The field leader for air sampling will ensure that all of the air filters are weighed, logged, and placed on the air monitors correctly.

\section{Air Monitoring Personnel}

Air monitoring personnel will assist the field team leader in setting up the monitors and loading and unloading the filters. The air monitoring personnel will be designated and trained by the field team leader. 


\section{Subcontractor}

Sonsub

Sonsub will be responsible for installing the hi-volume monitors and installing the tubes which will house the low-volume monitors. Sonsub is also responsible for conducting the CRD which includes earthwork, placement of the freeze pipes, ground freezing, and removal of the simulated waste.

\section{Safety Engineer}

\section{David Gray}

The safety engineer is respcnsible for reviewing the procedures in the test plan to ensure the procedures do not compromise the safety of any of the air monitoring personnel or Sonsub employees working with the air monitoring personnel.

\subsection{Test Personnel Qualifications and Training}

All test personnel involved in installing and removing the air monitors must be approved by the field team leader. All of these personnel must also be trained in using a self-contained breathing apparatus (SCBA). 


\section{DESCRIPTION OF TEST}

The CTP is split into five zones, large objects (not used during the CRD), stacked boxes (zone 1), stacked drums (zone 2), randomly dumped drums and boxes (zone 3), and randomly dumped drums (zone 4) (see Figure 1). Each zone has been spiked with a single rare-earth tracer as listed below:

\section{Zone 1 Neodymium Oxide 630.0 Grams \\ Zone 2 Terbium Oxide 15.5 Grams \\ Zone 3 Ytterbium Oxide 116.0 Grams \\ Zone 4 Dysprosium Oxide 40.5 Grams.}

For a more complete description of the CTP, refer to Engineering Dlesign File \# B'NP-151-009 by G. G. Loomis. ${ }^{\mathrm{a}}$

A $9 \times 9 \times 10 \mathrm{ft}$ block of earth and simulated waste will be frozen in each zone, except for the large objects zone. Each frozen block will be further divided into a "dry" portion and a "wet "portion (sce Figure 2). The term "dry" portion indicates the portion of the pit that will be frozen without the addition of any' moisture. The term "wet" portion indicates that water will the added to that portion of the pit. After each pit is frozen, icicles of frozen waste will be broken olf the pit and allowed to fall into an adjacent "working pit." The icicles will then be lifted out of the working pit into a storage box adjacent to the working pit (sce Figure 3). Each pit is separated into a wet and dry portion to determine if adding moisture to the pit improves the success of $\mathrm{CR}$.

A $26 \times 25 \times 45 \mathrm{ft}$ shell or enclosure will cover the frozen pit, the working pit, and the storage hox while the frozen waste is being extracted from the pit. A gantry for mounting equipment also serves as the frame for the enclosure. Low-volume air monitors will be distributed around this shell to sample the air while the extraction of the frozen waste is taking place.

The CRD will consist of eight test cases: dry and wet in zone 1 , dry and wet in zone 2, dry and wet in zone 3, and dry and wet in zone 4. Several low-volume samples will be taken during each of these test cases. Also, one 2-hour hi-volume sample will be taken inside of the weather shield before cach test case.

\subsection{Key Input and Output Condition:s}

The key input parameters will be the situation surrounding the test case (zone number and whether the portion of the pit is wet or dry before freezing). The ley output parameter will be the concentration of each tracer on each filter. The concentration will be defined in terms of milligrams of tracer per kilogram of dust.

a. Engineering Design File, BWP-151-009, "Design and Construction Details of the INEL Simulated TRU Test Pit," G. G. Loomis, March 1989. 


\subsection{Number of Tests, Location, and Schedule}

A total of 16 air monitoring tests will be run, 8 low-volume tests and 8 hi-volume tests. Ten monitors will be used during the low volume portion of the tests. One monitor will be used for each hi-volume test. Ten low-volume air monitors will be placed a long the sides of the weather shicld as shown in Figure 4. The hi-volume air samplers will be placed on the skids of the equipment gantry, one on the east side and one on the west side as shown in Figure 5. The low-volume samplers will run for as long as needed for Sonsub to break out all of the icicles for the respective test case. The present estimate is that each low volume sample will run for two, twelve-hour days.

The ten low-volume, $47 \mathrm{~mm}$, samplers located inside of the enclosure will be $\mathrm{r}$ innected to pumps via dacron tubing. The pumps will be located in a shed about ten feet from the outside of the gantry. The hi-volume samplers used for background sampling are both stand-alone units (see Figure 6).

\subsection{Test Method and Uncertainties}

A large concern for this test is the uncertainty of the air samplers capturing a significant amount of tracer from the CTP io determine the correct concentrations of tracers that may become suspended during the CRD. However, actual locations of the monitors are limited by safety, physical, and logistical constraints. Figure 4 displays the proposed locations of the monitors. Appendix A lists the assumptions and calculations used in determining the optimum monitor location for sampling any tracer release.

Since the concentrations of the tracers are going to be reported in mg(tracer) per $\mathrm{kg}$ (dust), the other major source of uncertainty is the presampling and postsampling weights of the filters. Factors that contribute to these uncertainties are the accuracy of the balance and the presence of moisture on the filters. The filters will be dried immediately before pre and posi sampling weights are taken. The accuracy of the scale is 0.0001 gram. Refer to Sections 5.3 and 5.7 for weighing procedures.

\subsection{Procedure}

Refer to Sections 4 and 5 of this document for detailed operating procedures.

\subsection{Illustrations}

Illustrations of the relationships of the pumps to the air monitors and weather shields and other equipment follow. Figure 7 shows a schematic of the equipment that connects the $47 \mathrm{~mm}$ low-volume monitors to the pump. Figure 8 shows the configuration of the monitors and pumps. Figure 9 describes the layout of the wiring inside the shed, and Figure 10 shows how the shed will be mounted. 


\subsection{Contingency Plans}

Once the gantry is set up over a zone, the hi-volume sampler's cannot be removed or changed out. If one of the samplers malfunctions, the second sampler will be used to sample before the "wet" portion of the pir is excavated. One hi-volume sampler should be kept on hand and calibrated to be used as a replacement if one of the samplers malfunctions. This change out can only be done while the equipment is being moved from one zone to another. The effect of losing one or more of the background data points to equipment malfunction is that there is less data for a regression analysis of the build up of tracer elements inside of the weather shield over time. This information is of only secondary concern to the overall CRD.

Adequate pumps, monitors, hoses, and fittings should be kept to serve as spares to the low volume samplers. As stated in Section 3.2, ten low-volume samplers should run during the removal of the icicles, the "breakout", for every test case. However, if safety concerns or equipment failures preclude this, the test will continue with the maximum amount (up to ten) of air monitors that are possible to run. The result of such a lack of equipment will be a reduction in the confidence level of the data. Refer to Tables 2 and 3 in Section 9.3.

\subsection{Performance Objectives}

The air monitoring personnel shall strive to deliver the high quality filter samples to the laboratory. Precautions necessary to ensure that filters are delivered to the laboratory in a pristine condition include handling the filters with tweezers, handling the filters gingerly so that none of the dust is knocked off of the filters, and leaving the pumps on ar the low-volume, 47-mm, air monitors are being pulled out $r^{c}$.ice tubes.

The performance objective of the pumps on the $47-\mathrm{mm}$ air monitors is to consistently pull enough air through the filters so that the filter is collecting dust during the entire "break out" operation. This will be monitored by monitoring the flow rate through each of the lines connecting the monitor to its respective pump.

The flow characteristics for each sample should be reported along with the sample number, location, test case, and net weight in a format similar to the one below:

Sample

Number

Location

Net

Average

Total Volume

\section{Nomber}

Data on the flow shall also be collected and stored so that curves which describe the flow rate and, thus, the soil build up on the filters can be generated similar to Figure 11. 


\section{SEQUENCE OF EVENTS}

A general sequence of events relating to the air monitors is listed in Table 1. This sequence can be modified at any time with verbal concurrence of Sonsub and the task manager or project manager. Modifications will be noted in the field logbooks. Requirements for the logbooks are listed in Section 6.3. If there is any change to procedures involving hazardous operations, a safe work permit must be issued by the safety engineer before the change can occur.

Table 1. Sequence of events for air monitors.

\section{Activity}

Dry and pre weigh sample filters. Record the lot and box numbers of the filter along with the sample number and the presampling weight in the field logbook.

See Section 5.2 for procedures.

Install the hi-volum: samplers in the equipment gantry.

Set up the gantry and weather cover.

Install filters in the two hi-volume monitors.

See Section 5.3 for procedures.

Start the hi-volume sampler on the eait side of the gantry for a 2-hour sample period.

Load filters into the low-volume samplers and place the samplers into the sampler holders.

After 2 hours, shut off the hi-volume sampler on the east side of the gantry.

Start the low-volume samplers.

Begin the removal of the icicles, the "breakout,"

in the "dry" portion of the pit.

Shut down for the evening.

Shut down the low volume samplers $1 / 2$ hour after the "breakout" activities have ceased for the day.
Performer

Field Team Leader

Sonsub

(one time only)

Sonsub

Air Monitoring

Personnel

Air Monitoring

Personnel

Air Monitoring

Personnel

Air Monitoring

Personnel

Air Monitoring

Personnel

Sonsub

Sonsub

Air Monitoring

Personnel or Sonsub 
Table 1. (continued).

Activity

Start the pumps for the low-volume samplers before activities begin for the day.

Continue with the "breakout" ot the "dry" pit.

Shut the low volume monitors down when the "break out" activities for the "dry" portion of the pit are finished.

Start the hi-volume sampler on the west side of the gantry.

Remove the low volume samplers from the sample holders. Remove the filter and ring.

Mount a new filter and ring.

Place the low-volume samplers with the new rings back into the sample holders.

Bring the old filter and ring back to the trailer.

Place the filter in the correct petri dish and make necessary notes in the field logbook.

Shut off the hi-volume sampler after it has run for 2 hours.

Start the low-volume samplers.

Begin the "breakout" of the wet pit.

S'. $s t$ down for the evening.

Shut down the low-volume samplers $1 / 2$ hour after the "breakout" activities have ceased for the day.

Start the pumps for the low volume samplers before activities begin for the day.

Continue with the "breakout" of the "we'." pit.

Shut the low-volume monitors down when the "break out" activities for the "wet" portion of the pit are finished.
Performer

Air Monitoring Personnel or Sonsub

Sonsub

Air Monitoring Personnel or Sonsub

Air Monitoring Personnel

A r Monitoring Personnel

Air Monitoring Personnel or Sonsub

Air Monitoring Personnel or Sonsub

Sonsub

Sonsub

Air Monitoring Personnel or Sonsub

Air Monitoring Personnel or Sonsub

Sonsub

Air Monitoring Personnel or Sonsub 
Table 1. (continued).

Remove the low-volume samplers from the sample holders.

Air Monitoring Personnel

Remove the filter and ring.

Bring the filter and ring back to the trailer.

Place the filter in the correct petri dish and make necessary notes in the field logbook.

Allow the weather shield to air out.

Remove the filters from the two hi-volume samplers.

Air Monitoring

See Section 5.4 for procedures.

Personnel

Move the weather shield to the next zone.

Sonsub

Repeat the above activities in the next zone.

After the "dry" and "wet" portions of a zone are completed, all of the filters from that zone will be hand carried to the Environmental Chemistry Unit (ECU). At the ECU, the air monitoring personnel will dry all of the filters to a constant weight $( \pm 0.0002 \mathrm{~g})$. The postsampling filter weight will be taken and recorded in the field logbook. The chain of custody of the filters will then be turned over to the ECU with the net weight (postsampling minus presampling) for each filter. 


\section{SAMPLING AND DATA COLLECTION}

The CRD involves using large amounts of liquid nitrogen to freeze soil and waste. This liquid nitrogen will be allowed to evaporate freely into the atmosphere. Consequently, there is concern that nitrogen gas will displace oxygen in the area around the gantry. Sections 5.3 through 5.6 describe changing out filters around the gantry. At least two people should approach the gantry and shed together. Both of these people must be wearing and breathing through self-contained breathing apparatus (SCBA).

\subsection{Chain of Custody}

A Chain Of Custody $(\mathrm{CO} C)$ for each filier will be initiated at the time when the presampling weight for the filter is taken. The COC will be tracked with EG\&G Idaho Form 114. The COC flow for each filter is shown in Figure 12. When the air monitoring personnel turn the COC over to the ECU, they will send the green copy of Form 114 to Donna Kirchner, MS 3904, to be filed under "Cryogenic Retrieval - WTD." The pink copy is sent to the task manager. The original COC form will be retained by the ECU. A copy of the COC will be delivered with the data package that includes the results of the analyses. The field team leader will be responsible for initiating the COC.

\subsection{PreSampling Filter Weighing}

Before taking the presampling weight, all filters will be cycled through an oven until a sample filter reaches a constant weight $( \pm 0.0002 \mathrm{~g}$ ). If there will be a lag time greater than 1 hour between removing the filters from the oven and weighing them, the filters should be left in a desiccator. A 5-place electronic balance with a current calibration sticker from the EG\&G Idaho Standards and Calibration Laboratory (S\&CL) will be used to determine these weights. This balance is located at the ECU. Once the sample filter has reached a constant weight, the rest of the filters will be weighed on the same balance. The weight for each filter will be recorded in the field logbook beside the sample number and lot number. The filter will be placed in a glass petri dish and sealed until used at the CTP. The sample label will be placed on the petri dish and the COC for the filter will be initiated using EG\&G Idaho Form 114.

The filters will always be handled using tweezers to minimize contamination of the filter from moisture and natural skin oils on the hand.

The number of filters to be weighed at one time will be determined by the field team leader.

\subsection{Installing Filters on the HI-Volume Air Monitors}

To install filters on the hi-volume air monitors, loosen and remove the filter cover. Handle the sample filter using tweezers to minimize contamination of the filter from moisture and natural skin oils from the hand. Remove an unused 4-in. filter from the petri dish and place on the filter head. Replace the filter cover, making sure the gasket is properly seated. Retain the petri dish for use during the next sample period. Petri dishes which correspond to filters mounted on samplers will be stored under the field team leader's custody. Start the hour meter and check the flow rate by checking the flow logger. Adjust the flow rate if it is less than $18 \mathrm{cfm}$ or greater than $22 \mathrm{cfm}$. The 
flow rate is adjusted by turning the adjustment screw with a screwdriver. This adjustment screw controls the motor speed which in turn controls the flow rate.

Note that SCBA and insulated gloves are required during this procedure. At least two people shall work together on this procedure. See Sections 5 and 12 for other safety requirements.

\subsection{Removing the Filters from the HI-Volume Air Monitors}

To remove filters from the hi-volume air monitors, loosen and remove the filter cover. Handle the sample filter using tweezers to minimize contamination of the filter from moisture and natural skin oils from the hand. Remove the used filter from the filter head and place the filter in the petri dish. Record the sample number, filter location, time, and date in the field logbook.

Note that SCBA and insulated gloves are required during this procedure. At least two people shall work together on this procedure. See Sections 5 and 12 for other safety requirements.

\subsection{Installing Filters into the Low-Volume Air Samplers}

To install filters into the low-volume air samplers, slide the air monitor out of the mounting tubing. Twist off the gold retaining ring. Using tweezers, remove an unused $47-\mathrm{mm}$ filter from a petri dish and place the filter inside of the gold ring. Twist the gold ring back on the monitor making sure that the filter is properly placed. Slide the monitor back inside of the PVC tube ensuring that the monitor is as far down the tube as possible without falling out of the end of the tube. Close the flap around the tube (see Figure 13). Handle the filters using tweezers to minimize contamination of the filter from moisture and natural skin oils on the hand.

Note that SCBA and insulated gloves are required during this procedure. At least two people shall work together on this procedure. See Sections 5 and 12 for other safety requirements.

\subsection{Removing and Exchanging Filters from the Low-Volume Air Samplers}

To remove exchanging filters from the low-level air samples, slide the air monitor out of the mounting tubing. Twist the retaining ring off of the monitor. Place another retaining ring on the monitor. If exchanging filters, this second retaining ring should contain a fresh $47-\mathrm{mm}$ filter (see Figure 13).

Place the used filter in a petri dish and record the sample number, location, and date in the field logbook. Handle the filters using tweezers to prevent contamination of the filter from moisture and natural skin oils on the hand.

Note that SCBA and insulated gloves are required during this procedure. At least two people shall work together on this procedure. See Sections 5 and 12 for other safety requirements. 


\subsection{PostSampling Filter Weighing}

Before taking the postsampling weight, all filters (from both hi- and low-volume samplers) will be cycled through an oven and desiccator until one sample filter reaches a constant weight $( \pm 0.0002 \mathrm{~g})$. Only one sample filter will be weighed during this cycle to minimize the amount of dust that is lost from the filters as they are transferred from the scale to the oven. A 5-place electronic balance with a current calibration sticker from the $S \& C L$ will be used to determine these weights. This balance is located at the ECU. Once the sample filter has reached a constant weight, the rest of the filters will be weighed on the same balance. The weight for each filter will be recorded in the field logbook beside the sample number and lot number. The net weight (postsampling weight) minus (presampling weight) will be recorded for each filter in the field logbook.

The filters will always be handled using tweezers to prevent contamination of the filter from moisture and natural skin oils on the hand.

After the post weights of the filters are recorded, the sample filters and COC will be turned over to the ECU. Air monitoring personnel will provide ECU the net weight for each filter. 


\section{DOCUMENT CONTROL}

\subsection{Data}

Data on the weight of the filters and their sampling locations will be recorded in the field logbooks as described in Section 5.

Data on air flow rates through the samplers will be read by an Omega data logger and recorded on a Compaq Laptop Personal Computer in units of cubic feet per minute (cfm). Data files will be downloaded from the PC onto floppy disks on a daily basis or more often if necessary.

\subsection{Test Plan}

During the CRD, some minor changes may have to be made to the procedures or sequence of procedures. Such minor changes may be necessary to improve the safety for the air monitoring or Sonsub personnel or to adjust to unforeseen equipment or logistical problems. Provided the changes do not effect procedures involving safety measures during hazardous operations, the changes may be made with verbal concurrence from the task manager, the field team leader, and Sonsub. These changes will be documented in the field logbook.

Any changes concerning the use of SCBAs, or rerouting of electrical wiring must have written concurrence from the safety engineer. This written concurrence may be in the form of an EG\&G Idaho Interoffice Correspondence signed or initialed by the safety engineer, or a safe work permit.

Other changes to the test plan will be made per Waste Technology Development Department Program Directive 1.5.

\subsection{Logbooks}

A logbook will be kept by the air monitoring personnel during set-up and conducting experiments. This logbook will be left in Sonsub's office trailer so that it can be accessed by all air monitoring personnel. This logbook will be issued from the INEL Technical Library per the EG\&G Idaho Resource Manual, Section $10 .^{c}$ The field team leader will be responsible for obtaining the logbooks and ensuring that proper procedures are followed in maintaining the logbooks. As a minimum, specific data that shall be included in the logbook for the work performed under this test plan are listed below:

- The locations of samplers during all tests

- Flow meter calibration information

- Flow meter readings

b. Waste Technology Department Standard Operating Procedures, Current Issuc.

c. EG\&G Idaho Resource Manual, Section 10, Current Issue. 
- Flow rates

- $\quad$ Filter pre and post weights

- Any changes made in experimental procedures

- Any test abnormalities observed

- Dates and information on all Quality Assurance (QA) samples blanks

- Any other pertinent information that the experimenter feels is necessary

- Wind velocity, humidity, and temperature as recorded at the National Oceanic and Atmospheric Administration (NOAA) station at the Radioactive Waste Management Complex (RWMC).

In addition, each page and entry into the logbook shall be dated with the name of the person making the entry.

The logbook will reference this test plan. With the exception of weekends, the field team leader will review and sign the logbook daily. 


\section{ANALYTICAL METHODS}

The analysis for determining the concentration of the tracers of the filters will be performed at the ECU. Inductively Coupled Mass Spectrometry (ISP-MS) will be a major part of this analysis. The details of the ICP-MS procedures are beyond scope of this test plan. Refer to ERD-SOW-110 and Standard Operating Procedures (SOP) for the filter digestion ${ }^{e}$ and ICP.-MS ${ }^{\mathfrak{f}}$ for these details.

d. ERD-SOW-110, Task Specific Statement of Work for the Inorganic ICP-MS Analyses for the Cryogenic Retrieval Project, April 1992.

e. S. J. Sailer, ECU-SOP-IP-1.3, June 1992.

f. S. J. Sailer, ECU-SOP-IP-1.6, June 1992. 


\section{DATA REDUCTION, VALIDATION, AND VERIFICATION}

\subsection{Data Reduction}

The amount of dust collected on each filter will be determined by subtracting the presampling weight of the filter from the postsampling weight of the filter. Refer to Sections 5.2 and 5.7 for details on these procedures.

The air flow rate for each pump will be monitored and the flow rate to each sampler will be calculated from linear calibration curves obtained from SC\&L for each flow meter. This data will be stored on a laptop PC and later down-loaded to a VAX work station or other PC to determine the average flow rate and the decrease in flow rate over time for each sample.

\subsection{Data Validation}

Data validation requires a systematic process for reviewing data against a set of criteria to provide assurance that the data are adequate for their intended use. The criteria for the filter data is that the location and test case recorded with the sample number is correct and is documented so that the data can not be lost. Filter data will be validated through the use of the COC procedures, see Section 5.1. Also, the field team leader will review the field logbooks, see Section 6.3.

\subsection{Acceptance Criteria}

All of the filter samples taken during the CRD will be recorded and forwarded to the ECU for analysis. Once the data on all of the filters is analyzed, the task manger will review the logbook to determine if any of the data should be rejected due to gross abnormalities during the CRD. If there are major equipment malfunctions during a portion of the CRD, the task manager, project manager, and field team leader may concur that the analysis of some filters will be futile and cancel the analyses of those filters. Refer to Tables 2 and 3 in Section 9.3 on how the loss of filter data will affect the confidence level in the data. 


\section{QUALITY ASSURANCE}

\subsection{Quality Level}

The quality level for the CRD is Waste Technology Development Department Program Plan, QPP-3378 and QPP-337 Addendum, QPP337-A001, ${ }^{\text {h }}$ which are the quality program plans this test plan will follow.

\subsection{Quality Control Methods}

Quality control of the filter handling during the CRD will be the responsibility of the field team leader. This will be controlled by the field team leader by ensuring that only qualified personnel handle the filters and make entries into the logbook. Properly followed COC procedures, described in Section 5.1, and logbook procedures, described in Section 6.3, will ensure this quality control. Field blanks will be randomly mixed with the sample filters which are brought to the ECU. Other quality control methods for the ECU are listed in ERD-SOW-110 (see footnote d).

\subsection{Completeness}

Flow meters will be connected to the pumps and monitored to ensure that the ten low-volume air monitors inside of the enclosure are running correctly during the necessary portions of the CRD. Each monitor should have a volume flow rate of at least $0.5 \mathrm{cfm}$. These air monitors will be located around the inside perimeter of the enclosure as shown in Figures 4 and 6. A test was conducted on May 18, 1992,to ensure that the configuration of pumps and monitors could sustain a necessary flow rate. Appendix $\mathrm{A}$ lists the assumptions made about how tracers will disperse within the enclosure and estimates of the number and location of the monitors that are necessary to detect any tracer resuspension during the $\mathrm{CRD}$.

The hi-volume monitors should have flow rates between $18 \mathrm{cfm}$ and $22 \mathrm{clm}$ and run for at least two hours.

Tables 2 and 3 illustrate how the number of low-volume filter samples affect the confidence level and error in the data.

The values listed in the tables are the values of the concentration of the rare-earth tracer (in $\mathrm{mg}$ of tracer per gram of dust) that would have to be found on one filter in order to reach the conclusion that the tracer originated from the spike in the CTP and not the natural background. For example, if all ten filter samples of Dysprosium are taken and one filter is found to have a concentration of 23.61 parts per million Dysprosium, one can be $95 \%$ confident from the data that tracer from the CTP reached the filter.

g. Waste Technology Development Department Quality Program Plan, QPP-337, Current Issue.

h. QPP-337 Addendum, QPP337-A001, Cryogenic Retrieval Demonstration, TPP\# ID-0604-DT, March 11, 1992. 
Table 2. Calculation of upper prediction limits when sample size $=10$. Values are in units of $\mu \mathrm{g} / \mathrm{g}$-dust and assume the concentrations are corrected for blank contannination.

\begin{tabular}{cccc} 
& \multicolumn{3}{c}{ Upper prediction limit } \\
\cline { 2 - 4 } Tracer & $90 \%$ & $95 \%$ & $99 \%$ \\
\hline Dy & 20.85 & 23.61 & 29.49 \\
$\mathrm{Nd}$ & 54.60 & 60.91 & 74.84 \\
$\mathrm{Yb}$ & 20.60 & 23.33 & 29.14 \\
$\mathrm{~Tb}$ & 19.35 & 21.35 & 25.62 \\
\hline
\end{tabular}

Table 3. Calculation of upper prediction limits when sample size $=5$. Values are in $॥$ nits of $\mu \mathrm{g} / \mathrm{g}$-dust and assurne the concentrations are correctcd for blank contamination.

\begin{tabular}{cccc} 
& \multicolumn{3}{c}{ Upper predictiol limi } \\
\cline { 2 - 4 } Tracer & $90 \%$ & $95 \%$ & $99 \%$ \\
\hline Dy & 18.22 & 21.09 & 27.10 \\
Nd & 48.59 & 55.13 & 68.88 \\
Yb & 18.01 & 20.83 & 26.78 \\
Tb & 17.44 & 19.52 & 23.89 \\
\hline
\end{tabular}

These tables summarize statistics from a study done in the spring of 1992. The filter samples were collected between March 30, and April 28, 1992. The air monitors werc located in the Subsurface Disposal Area of the INEL. Analysis of the filters was done using ICF'-MS. 


\section{EQUIPMENT AND INSTRUMENTS}

\subsection{Responsibility}

The Air Monitoring Equipment Coordinator, Mike Winberg, will be responsible for furnishing and calibrating all of the air monitoring equipment for the CRD.

\subsection{List of Equipment}

The following is a list of all of the equipment that shall be available at the start of the CRD. See Section 10.4 for calibration requirements.

$\begin{array}{lll}3 / 4 \text { HP motor } & \text { gas rotary vane pump } & 4 \\ \text { 1/4 HP motor } & \text { gas rotary vane pump } & 4 \\ 47 \mathrm{~mm} \text { Air Monitors } & \text { SAIC RADE CO. } & 16 \\ 47 \mathrm{~mm} \text { Filter Holders } & \text { SAIC RADE CO. } & 30 \\ \text { 47mm Glass Fiber Filters } & \text { SAIC RADE CO. } & 200 \\ \text { Glass Petri Dishes } & 5^{\prime \prime} & 15 \\ \text { Plastic Petri Dishes } & 3^{n} & 100 \\ \text { 3/8" Dacron Tubing } & 1000 \text { Feet } & 4 \text { rolls } \\ \text { Bourdon Tube Gages } & & 10 \\ \text { Swedgelock Fittings for 3/8" Tubing } & 14 \\ \text { Tool Shed } & \text { Including outlets and wiring by NEC code. } & 1 \\ \text { Hi-Vol Air Monitors } & \text { Anderson GMWL-2000 } & 3 \\ \text { 4" Glass Fiber Filters } & & 20 \\ \text { Flow Meters } & & 15 \\ \text { Data Logger } & & 1 \\ \text { Laptop PC } & & 1 \\ \text { Modem } & & 1 \\ \text { SCBA } & \text { Scott Air Pack } & 2 \\ \text { Insulated Gloves } & \text { (pairs) } & 4 \\ \text { Balance } & \text { Satorius 5 Place Balance } & 1 \\ \text { Chain of Custody Forms } & \text { EG\&G Form 114 } & 8 \\ \text { Oxygen Monitors } & \text { Sonsub } & 2 \\ \text { Generator } & \text { Sonsub } & 1 \\ \text { Safety Glasses } & & \text { AR } \\ \text { Face Shields } & & \text { AR } \\ \text { Hard hats } & & \text { AR }\end{array}$

\subsection{Range and Accuracy}

The motors and low-volume air monitors will be configured so that each monitor will be operating in the range of 0.5 to $3.0 \mathrm{cfm}$. The flow meters for the $1 / 4 \mathrm{in}$. lubing have an accuracy of $3 \%$ and a range of 0 to $7 \mathrm{cfm}$. The flow meters for the $3 / 8 \mathrm{in}$. tubing have an accuracy of $3 \%$ and a range of 0 to $3.33 \mathrm{cfm}$. The hi-volume samplers have a range of 18 to $22 \mathrm{cfm}$. 


\subsection{Calibration}

All gages and flowmeters will have a current calibration sticker from the EG\&G Idaho S\&CL. The hi-volume samplers and the Satorius 5-place balance will also have current calibration stickers from SC\&L. The SCBAs must be certified by the respirator maintenance facility. The oxygen monitors must have proof of calibration per Appendix D of the Sonsub Cryogenic Retrieval Project Safety Manual.' Calibration stickers are not required for any other instrumentation in this test plan.

\subsection{Preventive Maintenance}

The CRD will last a relatively short duration of time, approximately six weeks, so no preventive mrintenance schedule is necessary. Spare parts will be available during the CRD as listed in Section 10.2.

i. "Sonsub Cryogenic Retrieval Project Safety Manual," Appendix D, TAA250-B01-Revision 0, June 1992. 


\section{SUPPLIES, UTILITIES, AND FACILITIES}

Sonsub will furnish an 80 -amperage capacity generator to supply necessary power for the air monitoring equipment. Sonsub will also supply the oxygen monitors. 


\section{HEALTH AND SAFETY}

All of the personnel working with the air monitors within $40 \mathrm{ft}$ of the enclosure must be respirator trained and equipped with SCBA and warm gloves that provide adequate mobility to work in. No one may approach the gantry or shed alone. At least two people must work together in and around the gantry. Air monitoring persornel must only wear the SCBA which they are trained on, that is, the Scott Air Pack. A personal oxygen monitor may also be worn. The oxygen monitors must have proof of current calibration per the Sonsub Cryogenic Retrieval Project Safety Manual, Appendix D (see footnote i). The SCBAs must be inspected and tagged by a Health Physics Technician or Industrial Hygienist once a month. All work will be in compliance with the EG\&G Idaho Science and Technology Department Safety Program. ${ }^{j}$

The oxygen supply in the SCBA must be checked daily. The tanks must be refilled if the regulator reads less than 50\% full. Twenty-four hour notice must be given to Donna Miley (6-2487) so that she can ship the tanks to the Central Facilities Area to be recharged.

Eye glasses cannot be worn with the SCBA but contact lenses are allowed. If SCBA is worn, the mask must be sent to the respirator maintenance facility at the end of the work day to be cleaned before another person can wear the mask.

The following protective clothing is required for all personnel when they are changing filters:

Insulated gloves

Long s!eeves

Long pants

Safety shoes

Hard hats

Safety glasses with side shield (when not wearing the SCBA mask)

Face shield (when not wearing the SCBA mask).

Hearing protection shall be worn as required.

\subsection{Training}

All personnel wearing SCBA must have a current Respirator Fit Qualification.

\subsection{Electrical Safety}

Power cords for the air monitors must be protected from damage by vehicles and equipment. Outlets on the outside of the shed will be on a ground fault circuit interrupter. All electrical cords and sample tubing will be routed so as to minimize hazards from tripping.

j. Science \& Technology Department Safety Program, Current Issue. 


\section{RESIDUALS MANAGEMENT}

No hazardous or radioactive waste by-products will be generated from the work described in this test plan. 


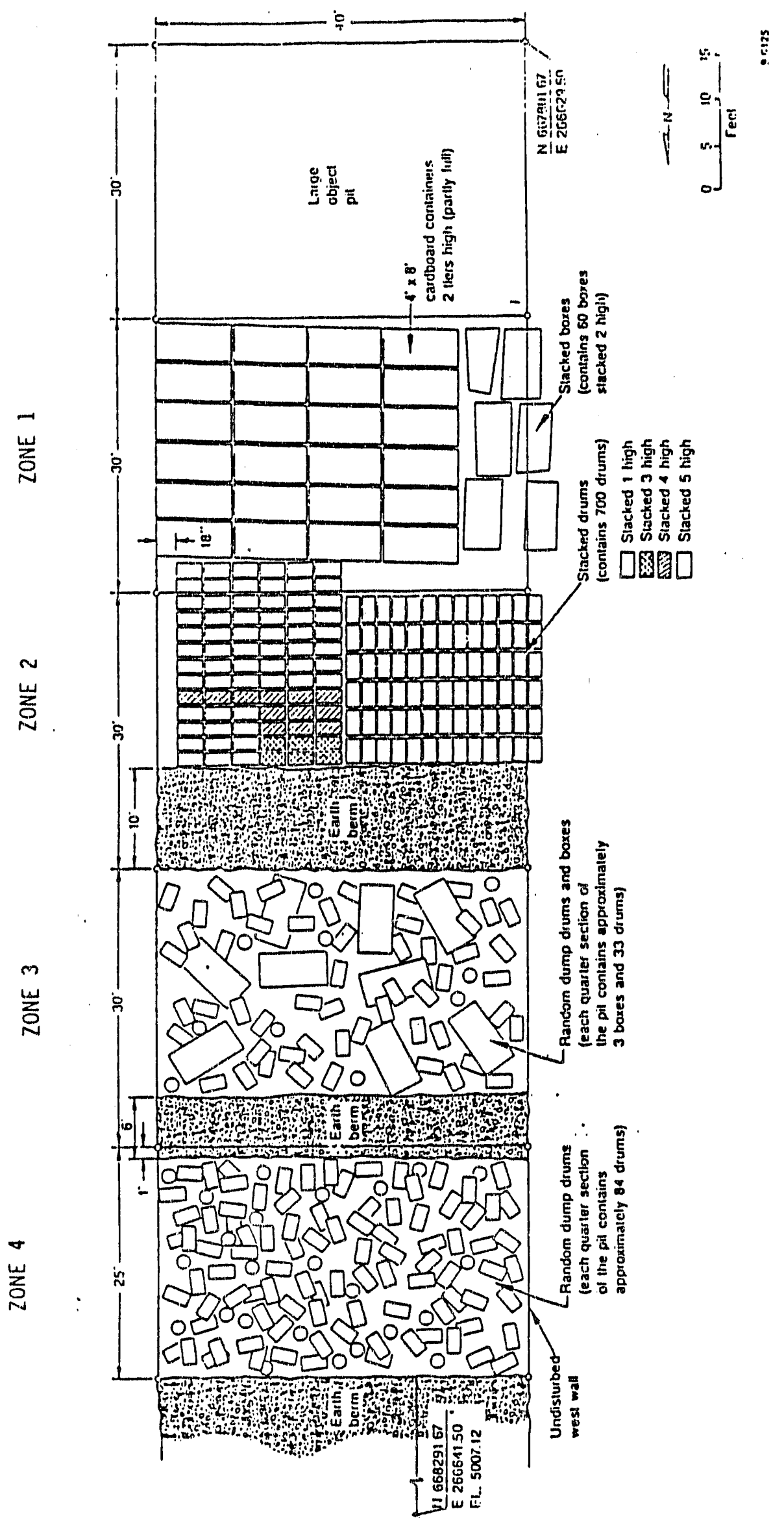

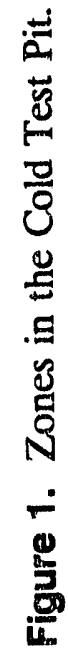




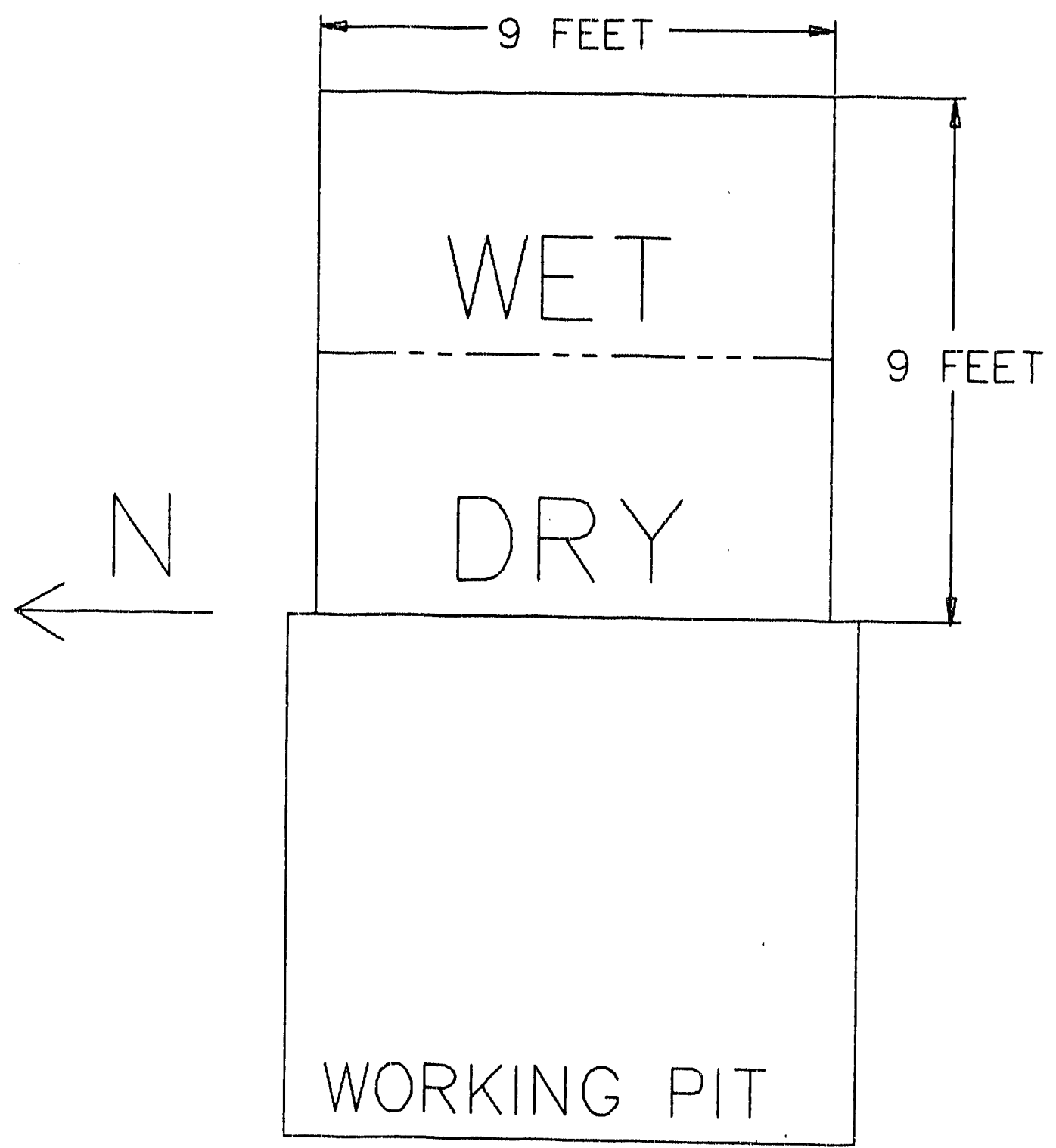

Figure 2. Top view of wet and dry portions of the pit. 


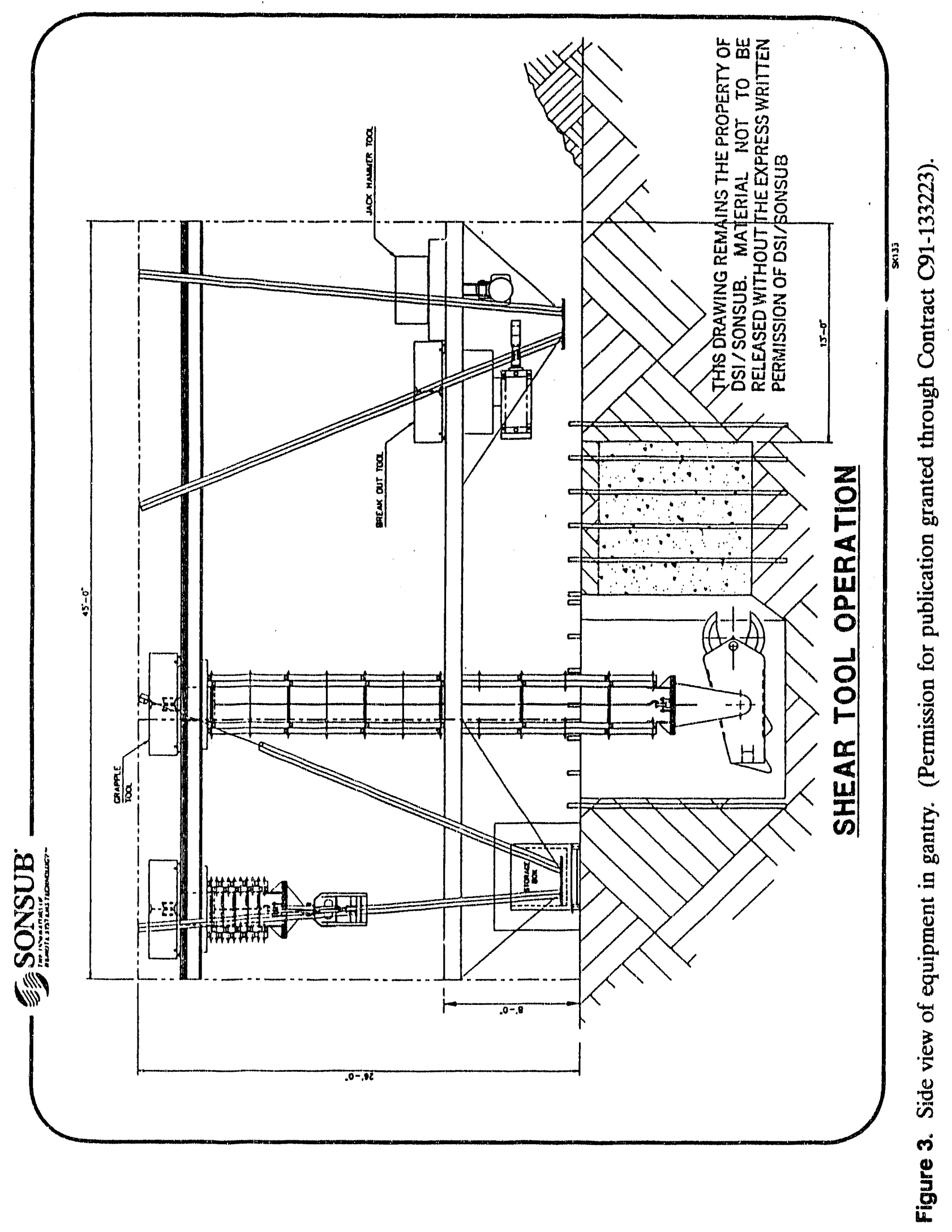




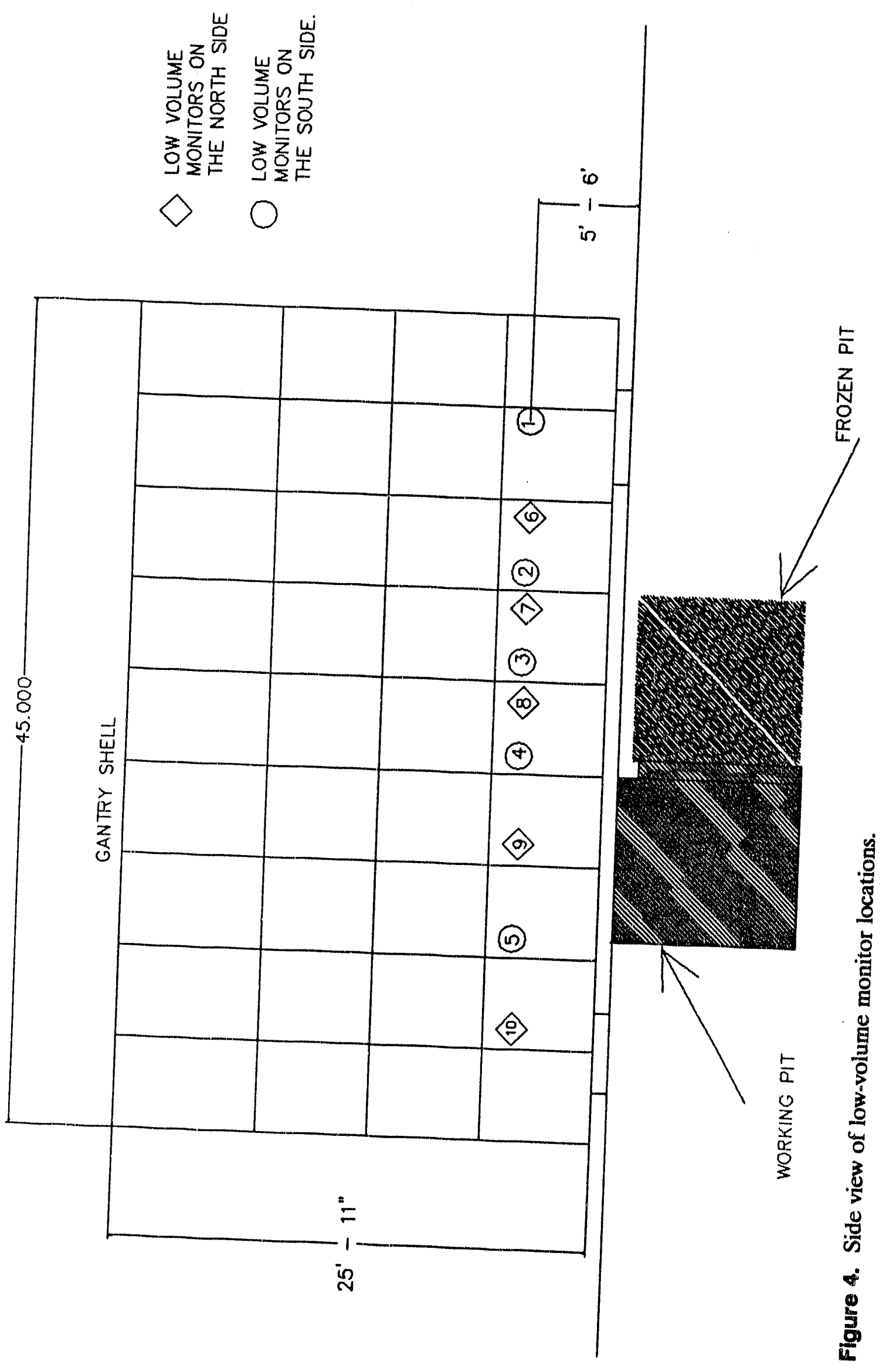




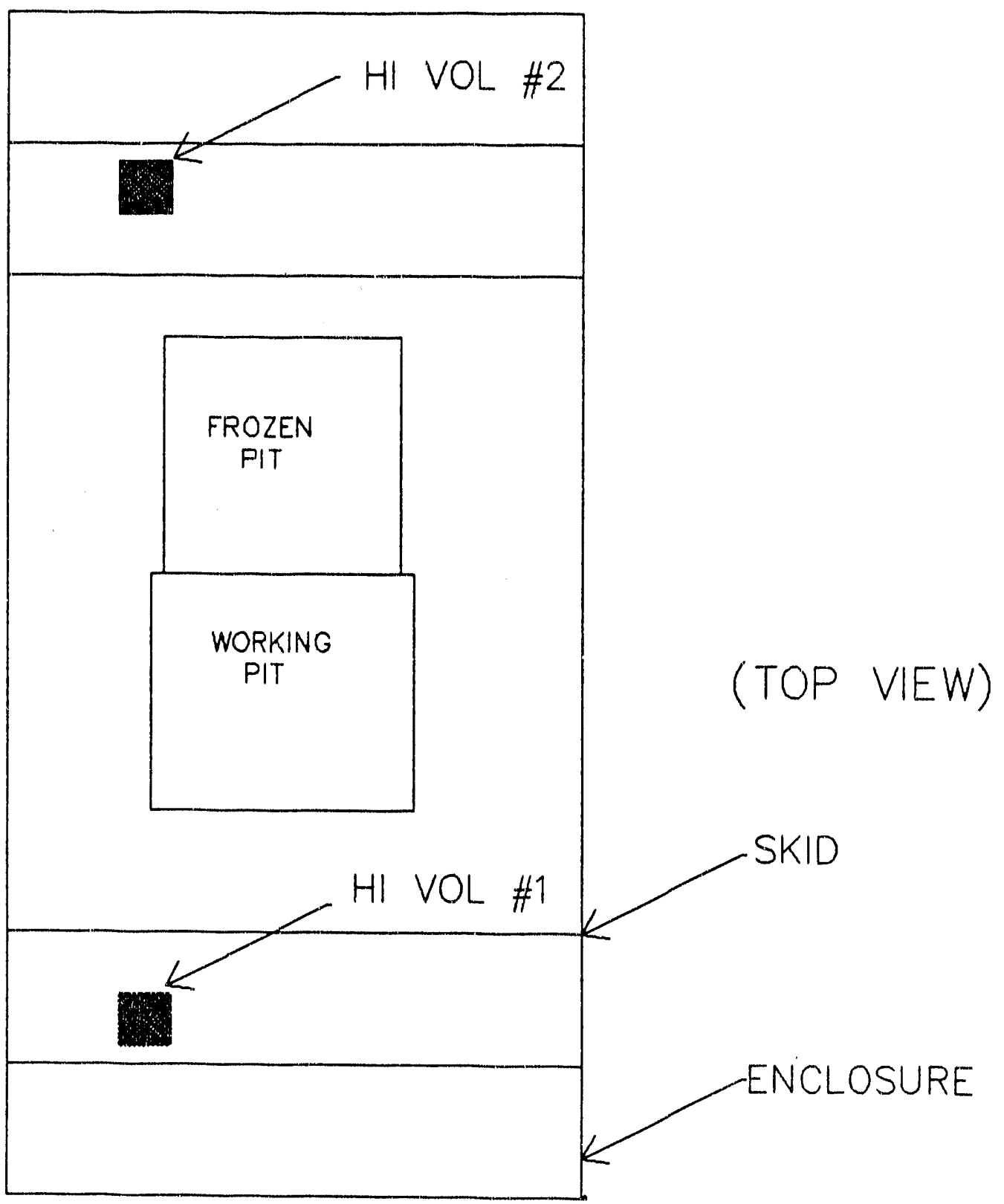

Figure 5. Location of hi-volume monitors. 


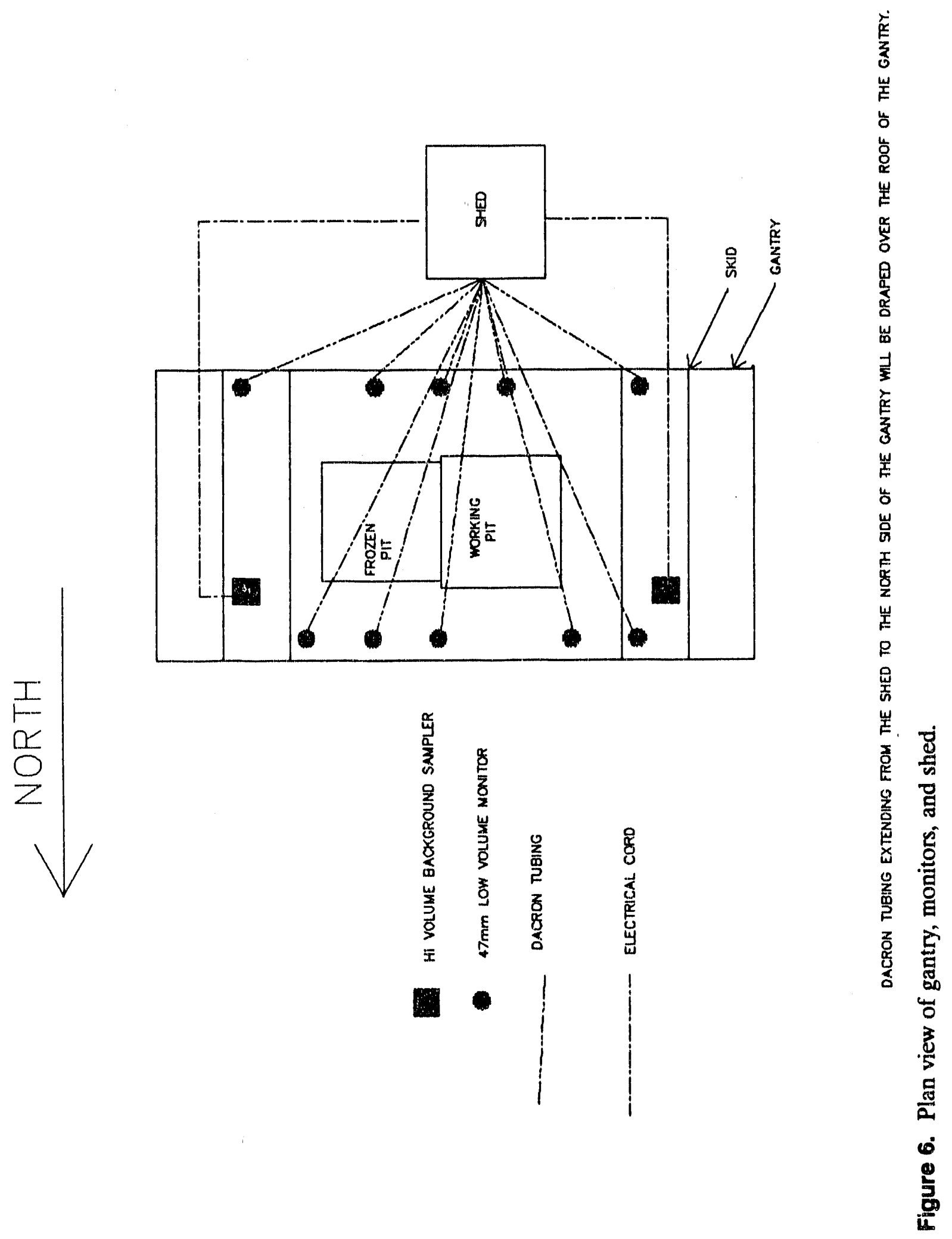




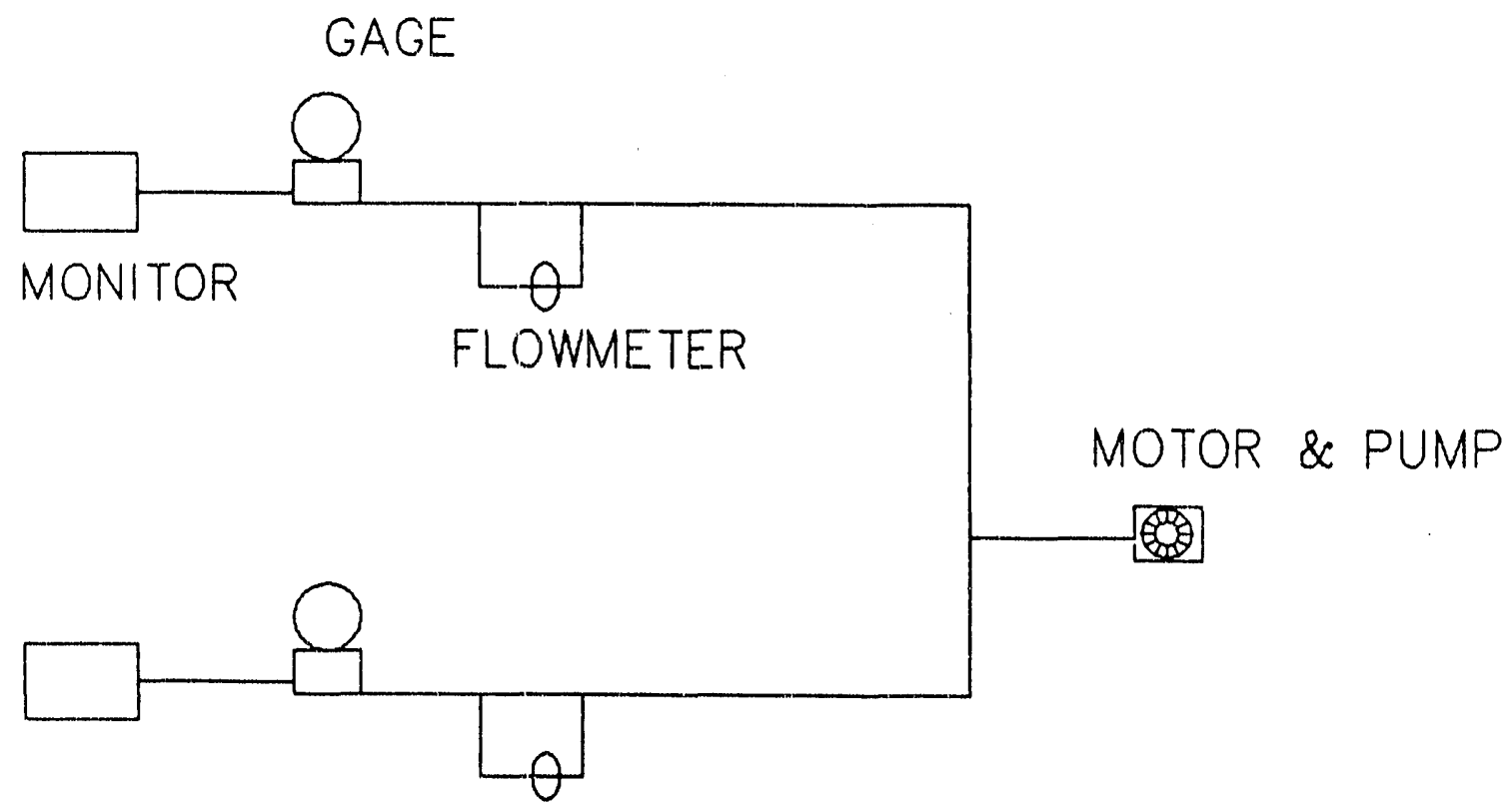

TYPICAL CONFIGURATION.

FOUR PUMPS

2 OR 3 MONITORS PER PUMP

Figure 7. Schematic of connections between low-volume monitors and pumps. 


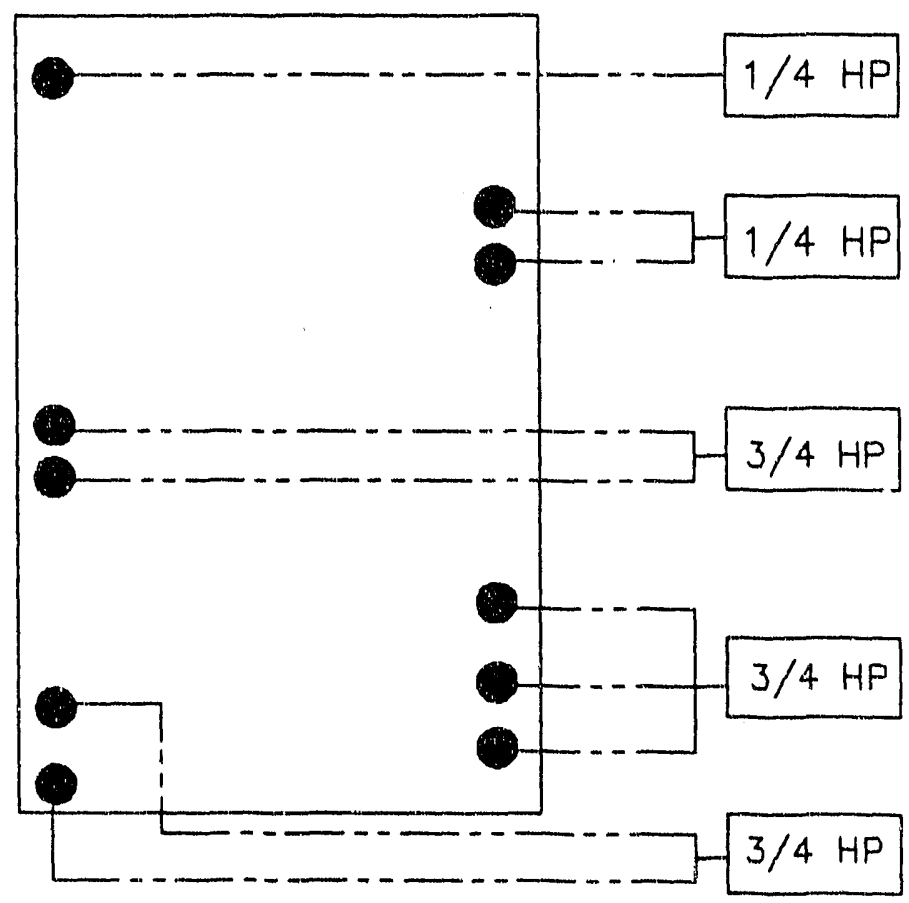

Figure 8. Schematic of pumps and monitors. 


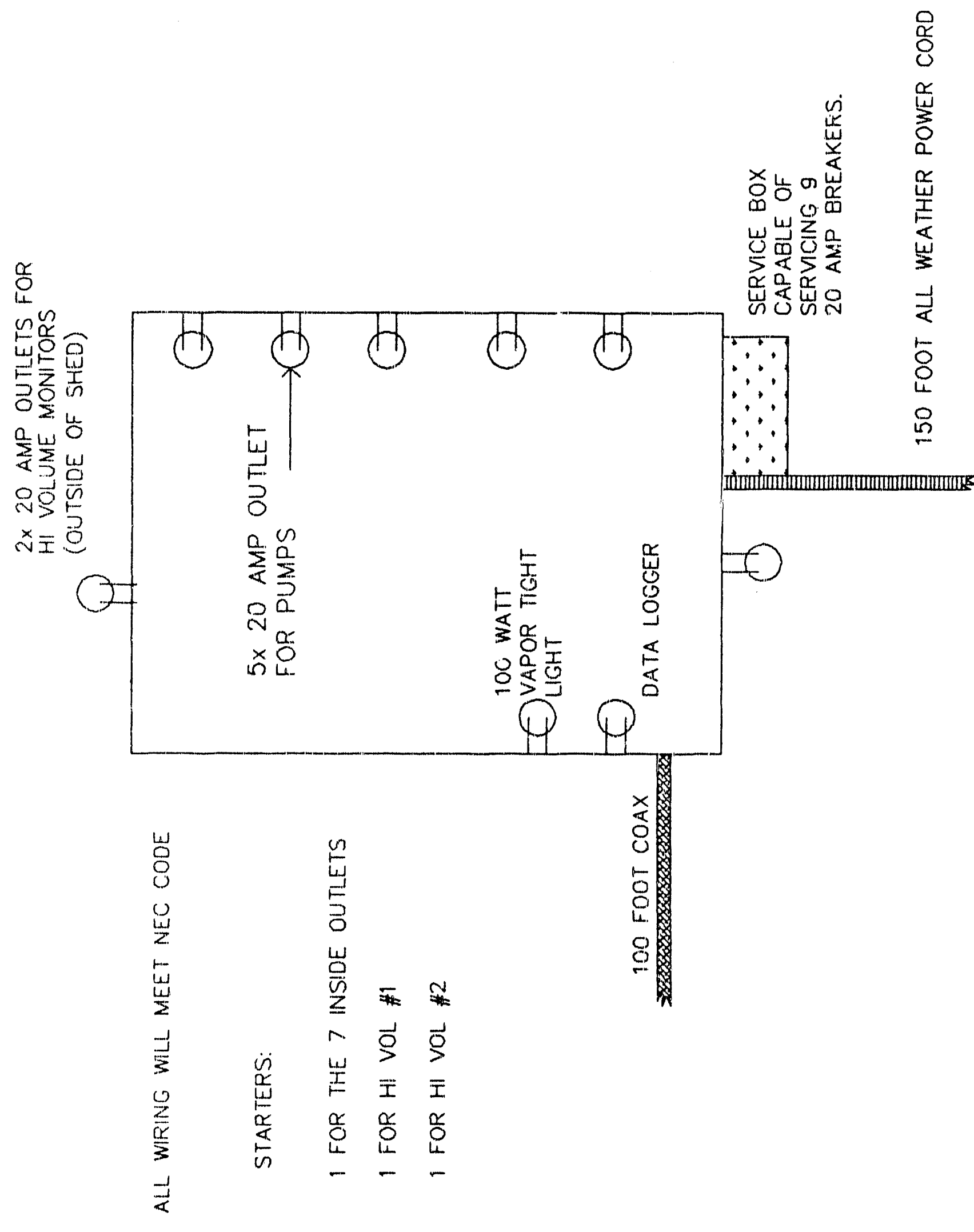

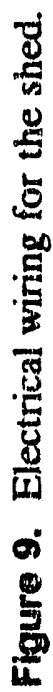




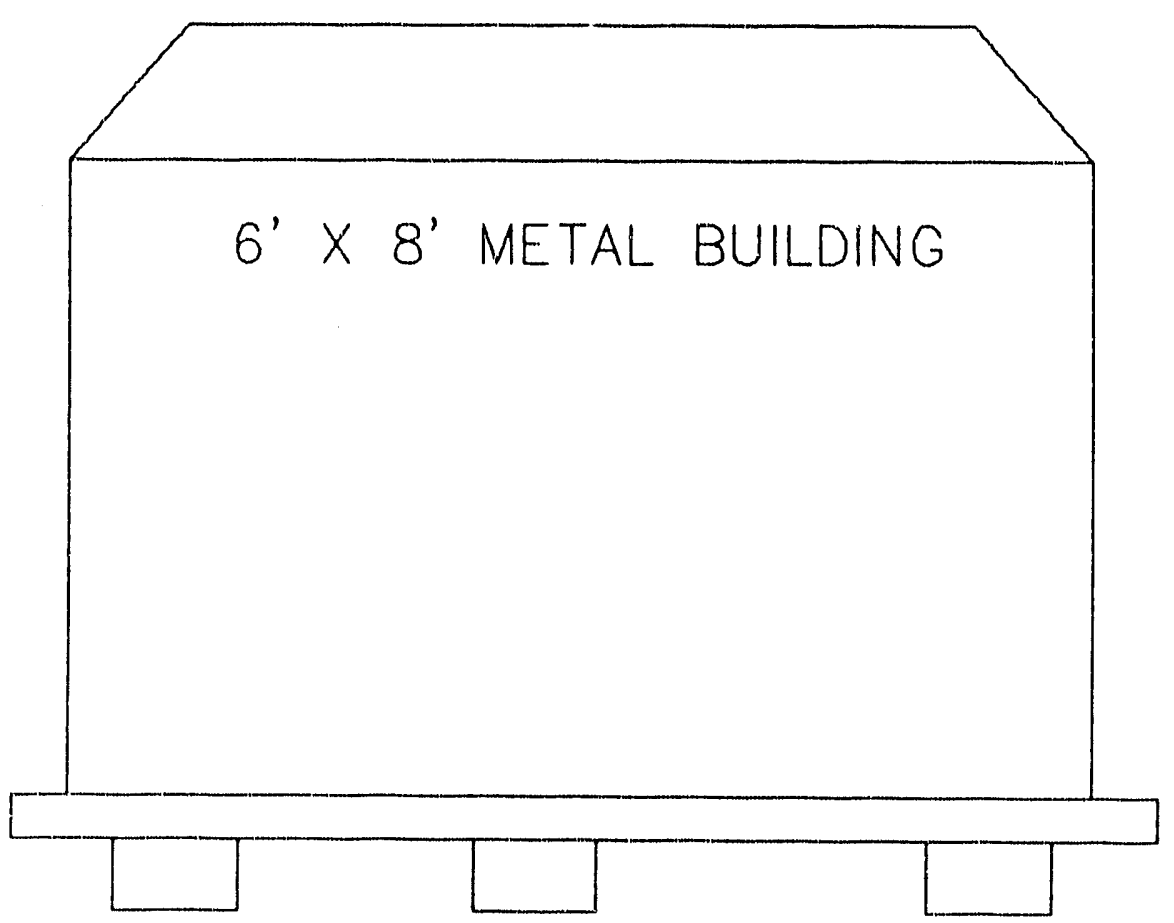

THE FLOOR IS BOLTED TO 4"X4" $\times 6$ " WOODEN BLOCKS THROUGH A FLOOR MADE OF 2" $\times 4$ " OR 2 " $\times 6$ " STOCK.

Figure 10. Mounting of the shed. 


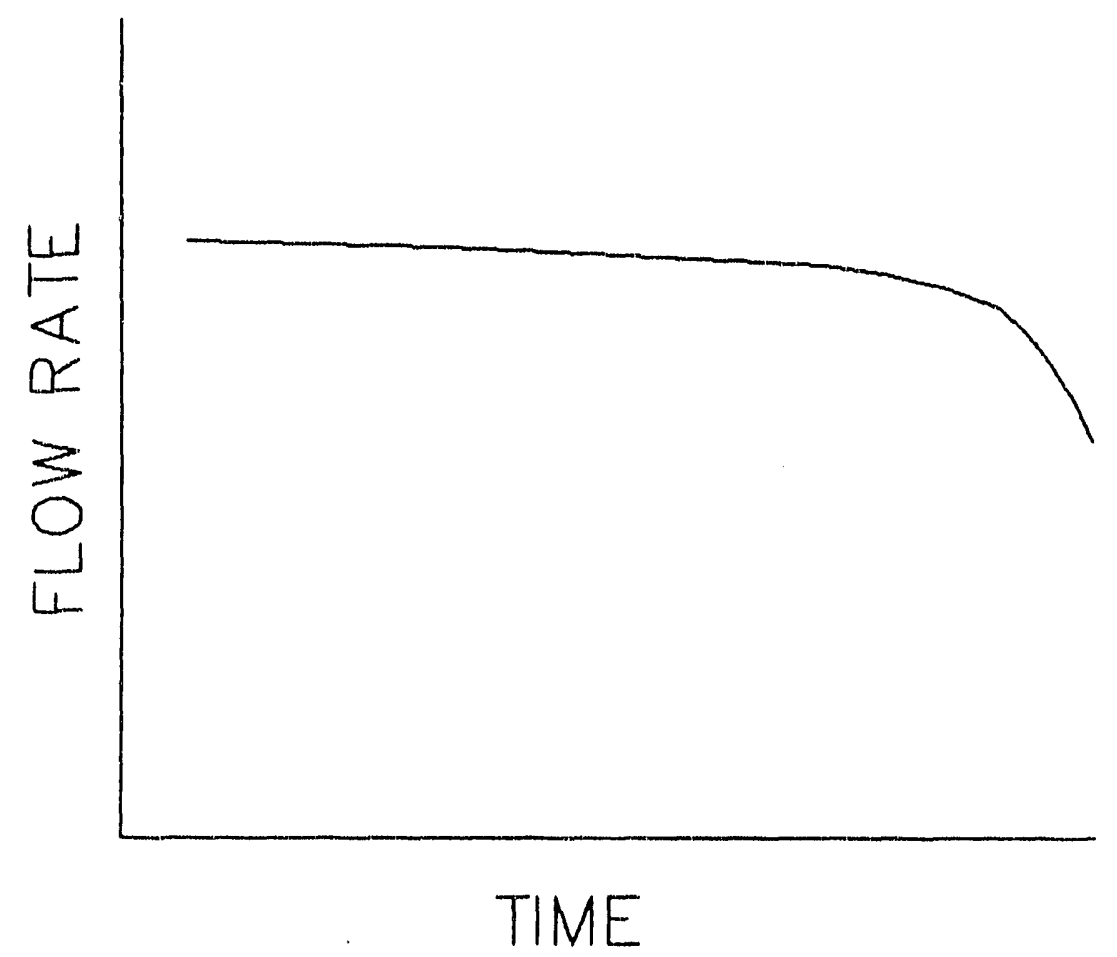

Figure 11. Example graph. 


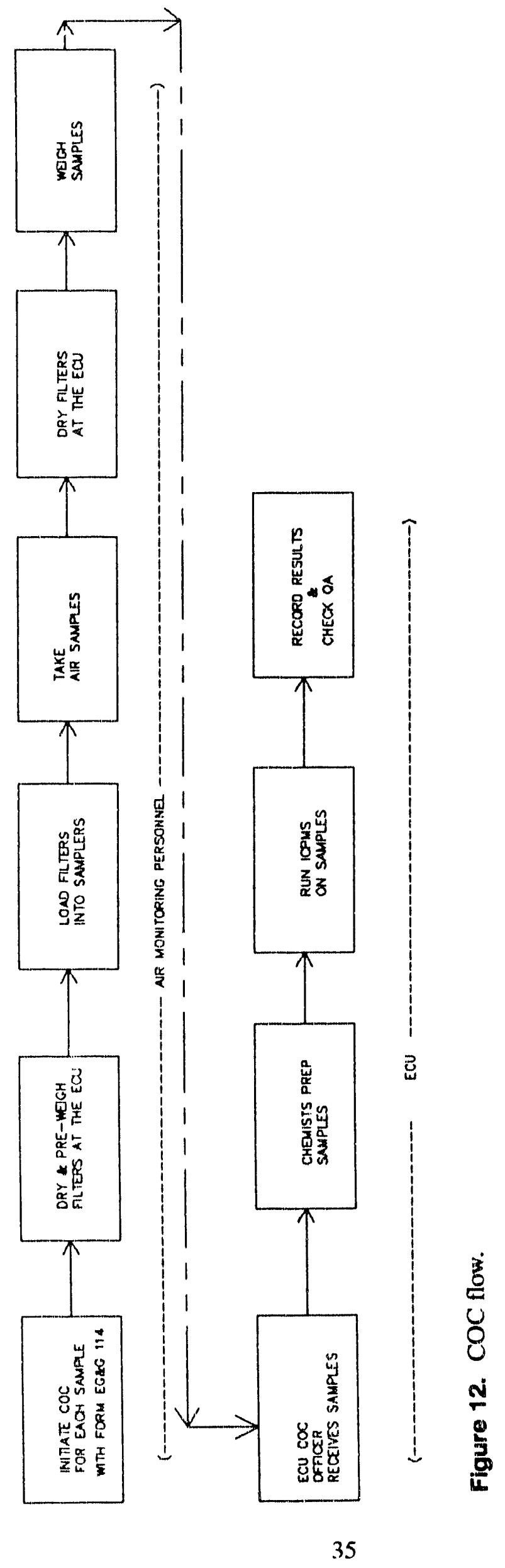




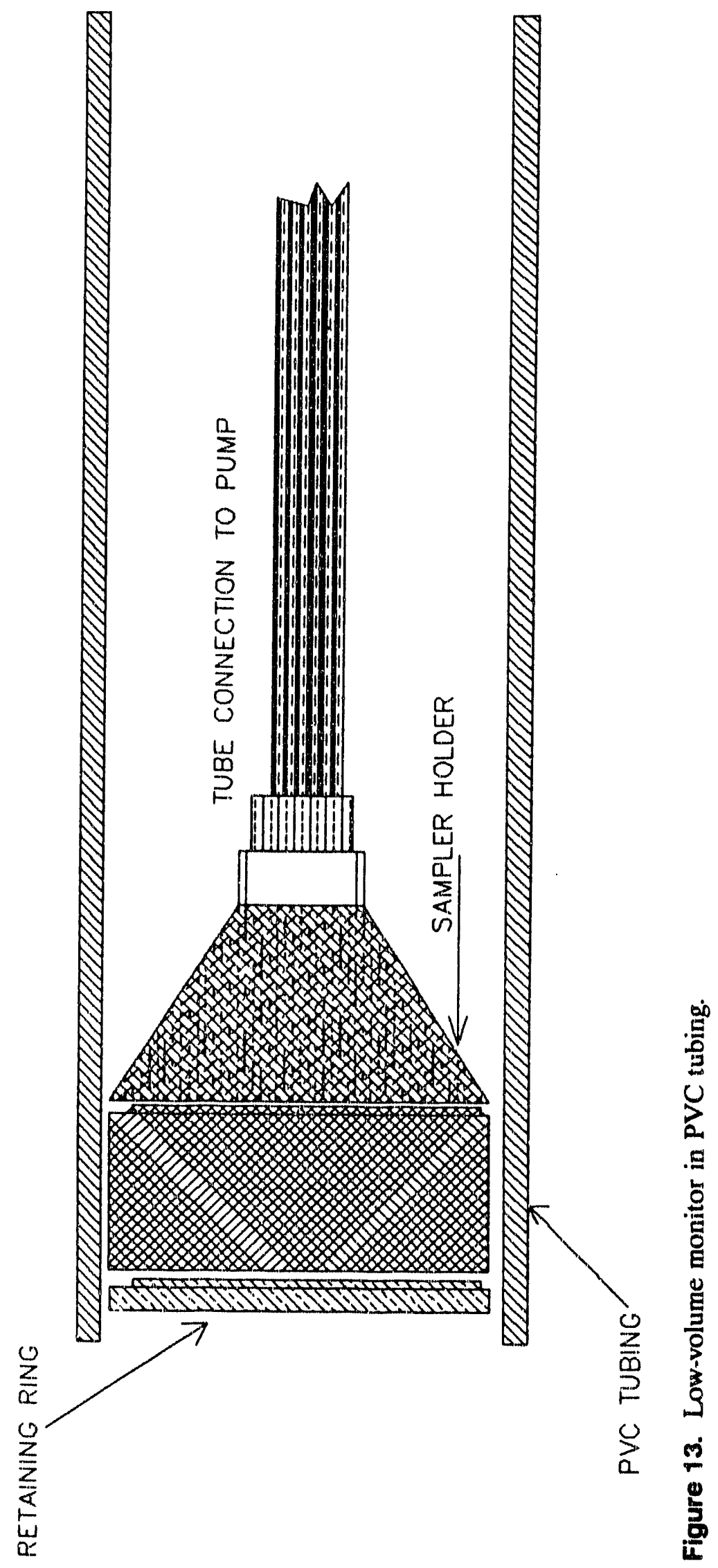




\section{Appendix A}

Assumptions on Tracer Movement 


$$
\text { A. } 2
$$




\section{Appendix A}

\section{Assumptions on Tracer Movement}

Because there will be no prevailing mechanisms inside of the gantry to create a predictable draft, it is assumed there will not be a dominate air flow in any direction inside of the enclosure. Thus, the exact motion of any tracer which may be released during the CRD is impossible to predict. The best empirical estimate that can be made about a release scenario is that there would initially be a large puff of dust which would eventually evenly disperse throughout the enclosure. The two questions that need to be asked are (1) how long will it take for the tracers to "settle out" (fall to the ground) and (2) how much tracer released from the pit needs to reach the monitors in order for the analysis to determine that a "significant amount," (see Section 1.3) of the tracer was released from the pit?

The average velocity for a tracer particle to settle out can easily be calculated from the Stokes equation for terminal velocity taken from section 11-6 of Reference A-1:

$V=\left(\frac{4 / 3 D\left(\gamma_{p}-\gamma_{Q}\right)}{C_{D} \rho_{a}}\right)^{1 / 2}$

where:

$\mathrm{V}=$ the average velocity of the particle in the vertical direction

$\mathrm{D}=$ the diameter of the particle

$\gamma_{\mathbf{1}}=$ the specific weight of air, taken from Reference A-1

$\gamma_{p}=$ the an average specific weight of the tracers, extrapolated from Reference A-2

$C_{D}=$ the drag coefficient

$p_{z}=$ the density of air, taken from Reference A-1.

Because the velocity and drag coefficient are codependent, this equation can be solved only by itcration. The program below does this iteration. The program assumes that all of the particles are spherical. This assumption can be made since the purpose of this exercise is only to get a rough idea of the amount of time that the particles would be suspended. 
CLEAR ALL

SET TALK OFF

SET ALTERNATE TO TV.OUT

SET ALTERNATE ON

**THIS IS A PROGRAM TO ESTIMATE THE TERMINAL VELOCITY OF A SPHERE

*V1 = FIRST GUESS AT VELOCITY

*V2=SECOND GUESS AT VELOCITY

${ }^{*} D=$ DIAMETER OF THE SPHERE

"Cd=DRAG COEFFICIENT OF THE SPHERE

*NU=KINEMATIC VISCOSITY OF THE FLUID

${ }^{*} \mathrm{RHO}=\mathrm{DENSITY}$ OF THE FLUID

*SWP=SPECIFIC WEIGHT OF THE PARTICLE

*SWF $=$ SPECIFIC WEIGHT OF THE FLUID

"SCIENTIFIC INTERNATIONAL UNITS ARE USED

*DEFINE VARIABLES

$\mathrm{V} 1=200$

$\mathrm{V} 2=10^{*} \mathrm{~V} 1$

$\mathrm{VNEW}=\mathrm{V} 1$

$\mathrm{D}=0.000004$

$\mathrm{NU}=0.000016$

$\mathrm{RHO}=1.4$

SWP $=89957.7$

$\mathrm{SWF}=13.7$

DO WHILE ABS(V1-V2) $>0.00000001$

$\mathrm{V} 1=\mathrm{VNEW}$

${ }^{*}$ CALCULATE REYNOLDS NUMBER TO ESTIMATE DRAG COEFFICIENT

$\mathrm{RE}=\left(\mathrm{V} 1^{*} \mathrm{D}\right) / \mathrm{NU}$

"ESTIMATE DRAG COEFFICIENT

*FROM PAGE 111 OF BUBBLES,DROPLETS, AND PARTICLES (sec Reference A-3)

IF RE $<1.0$

$\mathrm{Cd}=3 / 16+24 / \mathrm{RE}$

ENDIF

*

IF $1<$ RE .AND. RE $<1000$

$\mathrm{Cd}=(24 / \mathrm{RE})^{*}\left(1+0.125^{*}\left(\mathrm{RE}^{\wedge} .72\right)\right)$

ENDIF

*

IF RE $>1000$

$\mathrm{Cd}=(24 / \mathrm{RE})^{*}\left(1+0.15^{*}\left(\mathrm{RE}^{* *} .687\right)\right)+0.42 /\left(1+\left(42500^{*}\left(\mathrm{RE}^{* *}(-1.16)\right)\right)\right)$ ENDIF

*

$\mathrm{V} 2=\left(\left((4 / 3)^{*} \mathrm{D}^{*}(\mathrm{SWP}-\mathrm{SWF})\right) /\left(\mathrm{Cd}{ }^{*} \mathrm{RHO}\right)\right)^{* *} .5$

? V1, RE, Cd, V2

$\mathrm{VNEW}=\mathrm{V} 2$

ENDDO 
The time that a particle would remain suspended, $\Delta t$, was estimated from

$$
\Delta t=\frac{\Delta Y}{V} \quad \Delta Y=2 \text { meters }
$$

where it is assumed that the particle would become resuspended at 2 meters (approximately $6.5 \mathrm{ft}$ ).

Thus, the time that a particle will remain suspended and eligible to be sampled by one of the air monitors is dependent on the particle diameter as listed below.

\begin{tabular}{llll}
$\begin{array}{c}\mathrm{D} \\
\text { (microns) }\end{array}$ & \multicolumn{1}{c}{$\begin{array}{c}\mathrm{V} \\
\text { (meters/second) }\end{array}$} & $\begin{array}{c}\text { Settling Time from an Initial Height of } 2 \text { meters } \\
\text { (seconds) }\end{array}$ & (minutes) \\
\hline 0.1 & $2.2 \times 10^{-6}$ & $9 \times 10^{5}$ & 15151.0 \\
1.0 & $2.2 \times 10^{-4}$ & $9 \times 10^{3}$ & 151.0 \\
2.0 & $8.9 \times 10^{-4}$ & $2.2 \times 10^{3}$ & 37.0 \\
4.0 & $3.5 \times 10^{-3}$ & 571 & 9.5 \\
5.0 & 0.01 & 200 & 3.3 \\
10.0 & 0.02 & 100 & 1.66 \\
100.0 & 1.40 & 1.42 & $2 \times 10^{-3}$ \\
\hline
\end{tabular}

For small aerodynarnic response times, the particles will travel with the air. That is, one can assume that the tracer particles will go wherever the air goes. The aerodynamic response time, $\tau$, is defined as:

$$
\tau=\frac{\rho_{p} d^{2}}{18 \mu}
$$

where

$$
\begin{aligned}
& \rho_{p}=\text { the density of the tracer (from Reference A-2) } \\
& \mu=\text { the dynamic viscosity of the air (from Reference A-1) }
\end{aligned}
$$

The densities of the tracers range from $7200 \mathrm{~kg} / \mathrm{m}^{3}$ to $9170 \mathrm{~kg} / \mathrm{m}^{3}$. For scaling purposes, assume a density of $8000 \mathrm{~kg} / \mathrm{m}^{3}$ to see the effect of the particle diameter on the aerodynamic response time. 
(microns)

0.1

1.0

10.0

100.0 (seconds)

$2.69 \times 10^{-7}$

$2.69 \times 10^{-5}$

$2.69 \times 10^{-3}$

0.269

Since the aerodynamic response time is very small compared to the time that the tracers will be suspended, we can assume that the tracers will llow with the air.

The tracers' horizontal velocity, $U$, can be estimated as:

$\mathrm{U} \approx \frac{\Delta \mathrm{X}}{\Delta \mathrm{t}}$

As stated earlier in this exercise, there should not be one prevailing air flow inside the gantry. However, there should be air exchanges with the outside air on the order of 15 air changes per hour. $^{\mathrm{A}-4}$ Assuming that this infiltration will generate a unidirectional flow, $U$ can be estimated from the equation:

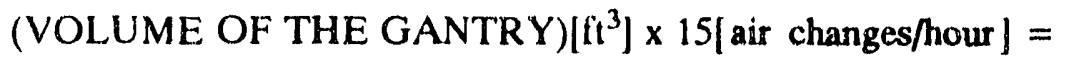

(SURFACE AREA OF THE GANTRY) [ft] $\times \mathrm{U}\left[\frac{\mathrm{ft}}{\mathrm{hr}}\right]$.

$$
\begin{gathered}
(45 \times 22 \times 26)(15)=(2(22 \times 26)+2(45 \times 26)) \times U \\
U=110.82 \mathrm{ft} / \mathrm{hr}=9.38 \times 10^{-3} \mathrm{~m} / \mathrm{s} \\
U \approx \frac{\Delta x}{\Delta t} \\
\Delta x \approx U \Delta t
\end{gathered}
$$

The average distance between the center of the pit and an air monitor is 11 feet or 3.35 meters. From the information above, the time for a suspended particle from the pit to reach an air monitor can be estimated. 
$\Delta t=\frac{\Delta x}{U}=\frac{3.35}{9.38 \times 10^{-3}}$

$\Delta t \approx 360$ seconds $=6$ minutes

Thus, tracer particles with diameters of 4 microns and less should remain suspended long enough to reach the air monitors. EDF BWP-151-009 (see Reference 1) lists the average diameter of the tracers to be 1 micron. This corresponds to an average suspension time of 2 hours. Most of these particles should reach the wall of the enclosure or an air monitor within 6 minutes of when they are released. It must also be noted that the velocities for the particles listed in the above analysis are only average. There are likely to be many high and low pressure zones created inside the enclosure which will cause a wide distribution of these velocities. This distribution is likely to enhance the mixing of any release and make it easier to detect.

Below is an analysis listing the amount of tracer which must be released from the pit and travel to one air monitor in order to determine if there is a significant release of tracer from the pit.

Use a Chebyshey bound distribution to find for background concentration with a $99 \%$ confidence level

$\operatorname{Pr}(|x-\mu|>k \sigma) \leq \frac{1}{k^{2}} \equiv 0.1 \quad k=\frac{1}{\sqrt{.01}}=10$

The following statistics were obtained from background sampling. Some of the means are less than zero because the statistics were adjusted for the concentration found on the field blanks.

\begin{tabular}{|c|c|c|c|c|}
\hline & & & $u$ & $a$ \\
\hline & $\mathrm{Nd}$ & & 6.95 & 19.12 \\
\hline & $\mathrm{Th}$ & & 4.21 & 6.07 \\
\hline & $\mathrm{Yb}$ & & -2.84 & 8.27 \\
\hline & Dy & & -4.34 & 8.37 \\
\hline$x=$ & $+k \sigma$ & & & \\
\hline & $\mathrm{Nd}$ & $\mathrm{Tb}$ & $\mathrm{Yb}$ & Dy \\
\hline$x=$ & 198.95 & 64.91 & 79.86 & 79.36 \\
\hline$x=$ & the maximum ppm, & $\frac{\text { tracer }}{\text { dust }}$ & , that could $b$ & dered coming from background. \\
\hline
\end{tabular}




\section{$T=$ total grams of dust in volume of air that passes through the enclosure assuming 15 air changes/hr for 12 hours}

$T=" \rho " . v$

$" \rho "$ = the dust loading in INEL air

$$
\frac{g \text { (dust) }}{\mathrm{cm}^{3} \text { (air) }}
$$

From NOAA, the HIGHEST LOADING is $77.2 \times 10^{-11} \frac{\mathrm{g}}{\mathrm{cm}^{3}}$

$\forall=$ the volume of air that passes through the enclosure in a 24 hour period.

$\forall=\left(\forall_{\text {enclosure }}\right)\left(15 \frac{\text { air changes }}{\mathrm{hr}}\right) \cdot(24 \mathrm{hr})$

$\forall_{\text {enclosure }}=22^{\prime} \times 45^{\prime} \times 10^{\prime}=9900 \mathrm{ft}^{3}$

(The actual height of the enclosure is 26 feet but we are assuming a 10 foot inversion ceiling.)

$\forall_{\text {enclosure }}=9900 \mathrm{ft}^{3} \times \frac{(12 \mathrm{in})^{3}}{\mathrm{ft}} \times \frac{2.54 \mathrm{~cm}^{3}}{(1 \mathrm{in})^{2}}=$

$\forall_{\text {enclosure }}=\left(280,336,781.26 \mathrm{~cm}^{3}\right) \cdot(15) \cdot(24)$

$$
=100,921,241,254
$$

$T=" \rho " v=\left(77.2 \times 10^{-11}\right) \cdot(100,921,241,254)$

$\mathrm{T}=77.91$ grams of dust in the air that will pass through the enclosure in 24 hours

To be conservation; let $\mathrm{T}=200 \mathrm{~g}$

Let $x=<\frac{\epsilon}{T+\epsilon} \approx \frac{\epsilon}{T}$

$$
\begin{aligned}
& \frac{\epsilon_{\mathrm{Nd}}}{200 \mathrm{~g}}=\mathrm{x}_{\mathrm{Nd}}=199 \times 10^{-6} \\
& \frac{\epsilon_{\mathrm{Tb}}}{200 \mathrm{~g}}=\mathrm{x}_{\mathrm{Tb}}=65 \times 10^{-6}
\end{aligned}
$$




$$
\begin{aligned}
& \frac{\epsilon_{\mathrm{Yb}}}{200 \mathrm{~g}}=\mathrm{x}_{\mathrm{YB}}=80 \times 10^{-6} \\
& \frac{\epsilon_{\mathrm{ldy}}}{200 \mathrm{~g}}=\mathrm{x}_{\mathrm{DY}}=79 \times 10^{-6}
\end{aligned}
$$

Thus, in order to detect a release, an air monitor must absorb at least:

$$
\begin{aligned}
& 0.040 \text { grams of neodymium } \\
& \text { or } \\
& 0.013 \text { grams of terbium } \\
& \text { or } \\
& 0.016 \text { grams of ytterbium } \\
& \text { or } \\
& 0.015 \text { grams of dysprosium. }
\end{aligned}
$$




\section{A-1. REFERENCES}

A-1. J. A. Roberson and C. T. Crowe, Engineering Fluid Mechanics, 2nd ed., Houghton Mifflin Company, Boston, 1980.

A-2. CRC Handbook of Chemistry and Physics, D. R. Lid ;, editor, CRC Press, Boston, 1990.

A-3. R. Clift, J. R. Grace, and M. E. Weber, Bubbles, Droplets, and Particles, Academic Press, New York, 1978.

A-4. ASHRAE HANDBOOK 1981 Fundamentals, American Society of Heating, Refrigerating and Air-Conditioning Engineers, Inc., Atlanta, 1982. 

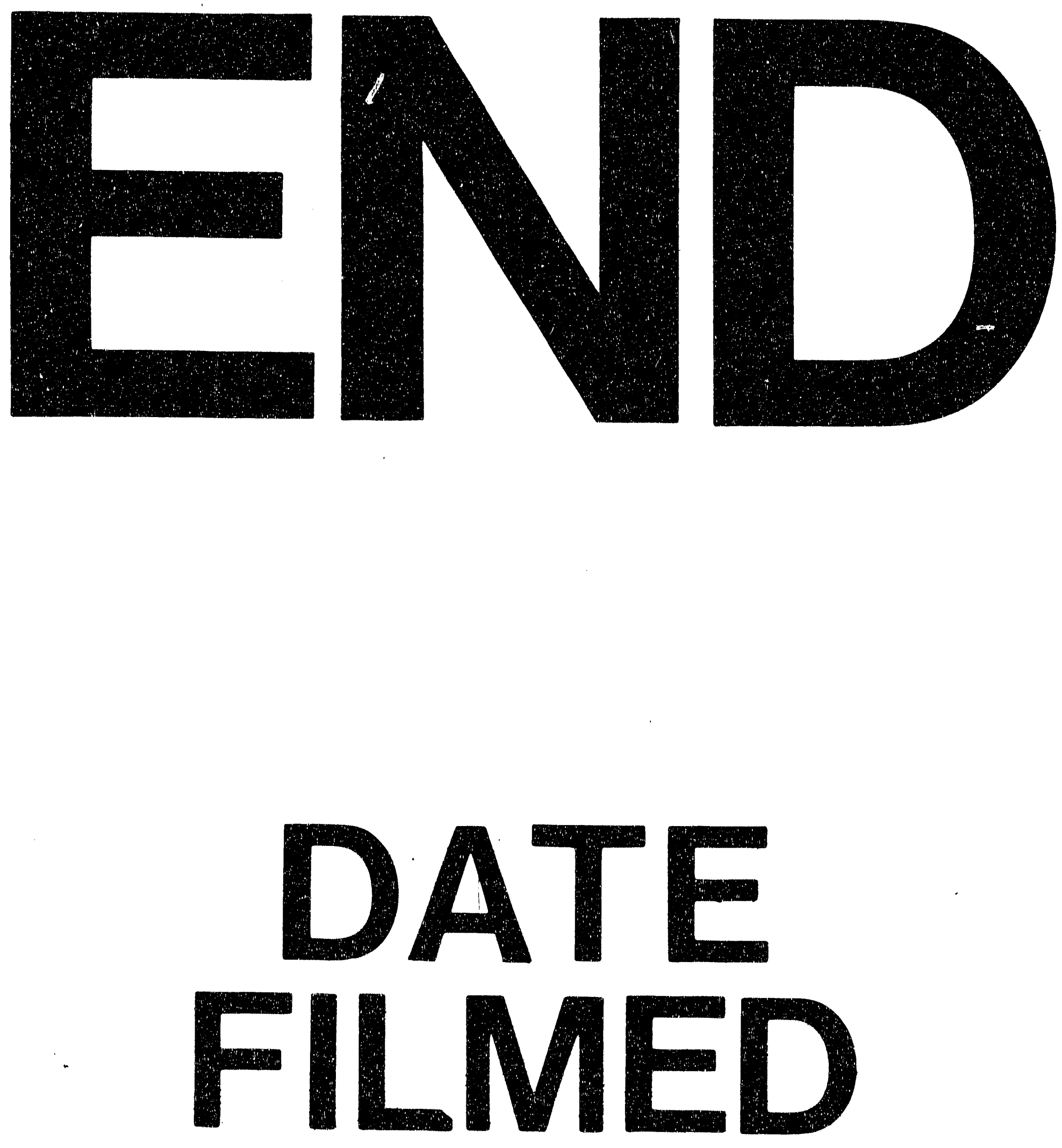

言

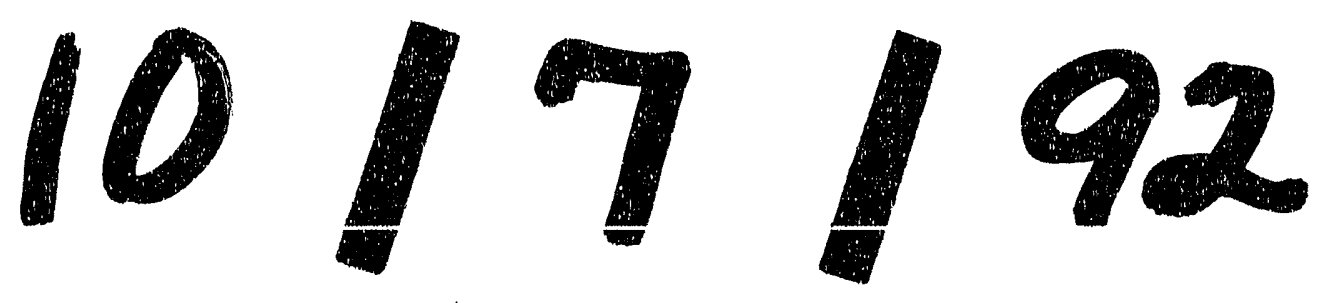


:

$\bar{\Sigma}$ 